\title{
Reorganization of Synaptic Connections and Perineuronal Nets in the Deep Cerebellar Nuclei of Purkinje Cell Degeneration Mutant Mice
}

\author{
M. Blosa, ${ }^{1}$ C. Bursch, ${ }^{1}$ S. Weigel, ${ }^{1}$ M. Holzer, ${ }^{1}$ C. Jäger, ${ }^{1}$ C. Janke, ${ }^{2}$ \\ R. T. Matthews, ${ }^{3}$ T. Arendt, ${ }^{1}$ and M. Morawski ${ }^{1}$ \\ ${ }^{1}$ Paul Flechsig Institute of Brain Research, University of Leipzig, Liebigstraße 19, 04103 Leipzig, Germany \\ ${ }^{2}$ Institut Curie, Centre de Recherche, CNRS UMR3348, Centre Universitaire, 91405 Orsay, France \\ ${ }^{3}$ Department of Neuroscience and Physiology, Sunny Upstate Medical University, 750 East Adams Street, Syracuse, NY 13210, USA \\ Correspondence should be addressed to M. Morawski; morm@medizin.uni-leipzig.de
}

Received 25 June 2015; Revised 10 September 2015; Accepted 15 September 2015

Academic Editor: Daniela Carulli

Copyright (C) 2016 M. Blosa et al. This is an open access article distributed under the Creative Commons Attribution License, which permits unrestricted use, distribution, and reproduction in any medium, provided the original work is properly cited.

\begin{abstract}
The perineuronal net $(\mathrm{PN})$ is a subtype of extracellular matrix appearing as a net-like structure around distinct neurons throughout the whole CNS. PNs surround the soma, proximal dendrites, and the axonal initial segment embedding synaptic terminals on the neuronal surface. Different functions of the PNs are suggested which include support of synaptic stabilization, inhibition of axonal sprouting, and control of neuronal plasticity. A number of studies provide evidence that removing PNs or PN-components results in renewed neurite growth and synaptogenesis. In a mouse model for Purkinje cell degeneration, we examined the effect of deafferentation on synaptic remodeling and modulation of PNs in the deep cerebellar nuclei. We found reduced GABAergic, enhanced glutamatergic innervations at $\mathrm{PN}$-associated neurons, and altered expression of the $\mathrm{PN}$-components brevican and hapln 4 . These data refer to a direct interaction between ECM and synapses. The altered brevican expression induced by activated astrocytes could be required for an adequate regeneration by promoting neurite growth and synaptogenesis.
\end{abstract}

\section{Introduction}

The function of the nervous system is based on a precise composition and maintenance of a neuronal and synaptic network. The connectivity of the brain is formed during a period of enhanced plasticity in development when appropriate synaptic connections are stabilized in an activity dependent manner. In contrast, once the adult connectivity is established, plasticity of some synaptic contacts is greatly diminished. Functional alterations as they occur in many brain disorders are also accompanied by remodeling of neuronal structures, changes in neuronal activity, and loss of neuronal molecules [1-3]. A number of studies demonstrated that several extrinsic [4-7] and intrinsic [1-3, 8, 9] changes are associated with alterations in synaptic density or shape, dendritic outgrowth, and even extracellular matrix molecules. Especially a specialized form of the extracellular matrix, the perineuronal net, often shows alterations in neurodegenerative diseases [8-11] and acute brain injuries [7, 11-15] and is suggested to prevent regeneration. These perineuronal nets (PNs) enclose the cell bodies and the proximal dendrites of specialized neurons thereby embedding the contacting synaptic boutons [16-18]. PNs are composed of aggregating chondroitin sulphated proteoglycans (CSPGs), hyaluronan, hyaluronan binding link proteins (hapln), and tenascin-R [19-22]. CSPGs of PNs belong to the lectican family including the main members aggrecan, brevican, and neurocan, while aggrecan is prominently detected in PNs $[23,24]$. Most of the PN-components are produced by neurons and glial cells, but a few constituents are made by only one of these cell types $[25,26]$. PNs are involved in organizing extracellular space, modulating synaptic plasticity, and providing a special extracellular ionic milieu and synaptic stabilization [16, 2732]. The formation and maintenance of $\mathrm{PNs}$ in a number of 
systems are activity dependent [31, 33-36]; thus they mainly occur at highly active neurons and altered activity disrupts PN formation [27, 34, 35, 37-42]. To analyze the potential role of PNs in degeneration/regeneration of slow denervation processes and to analyze the declining influence of synaptic input on PNs we use a mouse model for Purkinje cell degeneration ( $p c d, p c d-3 j / J$ model). The pathology is caused by a mutation of the Nnal gene $[43,44]$ encoding a protein also known as cytosolic carboxypeptidase 1 (CCP1) $[45,46]$, which has been demonstrated to be involved in the enzymatic deglutamylation of proteins, and in particular of tubulin [47]. It was therefore suggested that neurodegeneration in the $p c d$ mouse is induced by a hyperglutamylation of microtubules in the affected neurons. In a rescue experiment the depletion of the tubulin tyrosine ligase-like protein 1 (TTLL1) [48] could partially prevent degeneration of the Purkinje cells (PCs) [47].

The PCs as part of the cerebellum are involved in motor coordination and posture control; as consequence in the pcd$3 \mathrm{j} / \mathrm{J}$ model a loss of PCs leads to a moderate ataxia beginning at 3-4 weeks of age [43]. In addition, the degeneration of PCs is accompanied by the loss of cerebellar granule neurons [43, 49], olfactory mitral cells [50], some thalamic neurons [43], and alterations in retinal photoreceptors $[50,51]$. Before PCs degenerate, which starts $\sim \mathrm{P} 18$ and proceeds until $\sim \mathrm{P} 45$, the PCs and their synaptic contacts show a normal development [52].

The GABAergic PCs receive virtually all input from within the cerebellum and provide the exclusive output of the cerebellar cortex, mainly inhibiting neurons of the deep cerebellar nuclei (DCN). The cells of DCN are a heterogeneous population of inhibitory and excitatory neurons [53-57], but only the large excitatory DCN neurons are surrounded by the condensed specialized extracellular matrix of PNs [25, 58-60]. However, it was repeatedly demonstrated that PNassociated neurons are protected against different neurotoxic insults and degenerative processes while neurons without a $\mathrm{PN}$ are not $[8,13,61,62]$.

Here we are investigating the integrity and expression of PNs and their components as well as the synaptic innervation and remodeling of DCN neurons after the degeneration of their main GABAergic input, the PC axons. The PNassociated DCN neurons showed an imbalance of inhibitory and excitatory innervations. We found a reduced GABAergic synaptic input and simultaneously these neurons receive an increased glutamatergic input. Further, the cytochemical analyses showed that the molecular composition of PNs has changed and revealed that brevican and hapln 4 are prone to the degeneration processes and may influence the regeneration of the injured tissue.

\section{Experimental Procedures}

2.1. Animals. Data were collected from $11 \mathrm{pcd} 3 \mathrm{j}$ (C57BL/6$\operatorname{Agtpbp1}^{\text {pcd-3j}} / J$, Stock \# 003237) knock out mice and 11 wild type $(w t)$ littermates ( 6 mice of each genotype for immunocytochemistry and 5 mice of each genotype for biochemistry) of both types of sex at the age of 4 months. Animals were genotyped as juveniles by PCR as described on The Jackson Laboratory's website (Genotyping protocol database of the Jackson Laboratory). They had free access to food and water and were maintained on a $12 / 12 \mathrm{~h}$ light-dark cycle under conditions of constant temperature $\left(22^{\circ} \mathrm{C}\right)$. All animals used in this study were treated in agreement with the German law on the use of laboratory animals. The ethical guidelines of the laboratory animal care and use committee at the University of Leipzig were followed.

2.2. Cytochemistry. The animals were deeply anesthetized with $\mathrm{CO}_{2}$ and perfused transcardially with $10 \mathrm{~mL} 0.9 \% \mathrm{NaCl}$ following $100 \mathrm{~mL}$ fixative containing 4\% paraformaldehyde and $0.1 \%$ glutaraldehyde in $0.1 \mathrm{M}$ phosphate buffer $(\mathrm{pH} 7.4)$. Brains were removed and postfixed in the same fixation solution overnight. The tissue was cryoprotected in $30 \%$ sucrose with $0.1 \%$ sodium azide, cut in $30 \mu \mathrm{m}$ thick slices with a cryomicrotome in frontal planes, and collected in phosphate buffer containing $0.1 \%$ azide.

Before staining, tissue was pretreated with $60 \%$ methanol containing $2 \% \mathrm{H}_{2} \mathrm{O}_{2}$ for $20 \mathrm{~min}$ followed by a blocking step with a blocking solution containing $2 \%$ BSA, $0.3 \%$ milk powder, and $0.5 \%$ donkey serum in phosphate buffer for $1 \mathrm{~h}$. All the antibodies (see Table 1) were incubated in blocking solution overnight at $4^{\circ} \mathrm{C}$. The visualization was performed by standard fluorescent secondary antibodies (see Table 2). Identification of the investigated brain areas was made by brain atlas of mouse [72].

2.3. Imaging Procedures. Tissue sections were examined with a Zeiss Axiovert $200 \mathrm{M}$ microscope (Zeiss, Jena, Germany) and a Zeiss confocal laser scanning microscope (Zeiss, Jena, Germany; LSM 510 meta). Confocal images of carbocyanine dye 2 (Cy2) fluorescence were obtained with the Argon laser $(488 \mathrm{~nm})$ and emission filter BP 505-530. The HeNe 1 laser $(543 \mathrm{~nm})$ and the emission filter BP 560-615 were used to detect the carbocyanine dye 3 (Cy3) fluorescence, respectively. Photoshop CS2 (Adobe Systems, Mountain View, CA, USA) was used to process the images with minimal alterations to the contrast and background.

2.4. Quantification. To estimate molecular alterations in pcd mice frontal sections were investigated and PN-bearing neurons of nucleus interpositus and nucleus dentatus of the DCN and the nucleus vestibularis lateralis were analyzed. The sections were labeled with anti-human aggrecan antibody (HAG7D4), the most comprehensive marker for PNs and additionally with GAD65/67 or vGlutl and 2 for double immunofluorescence counting. The tissue was analyzed with a Zeiss Axiovert $200 \mathrm{M}$ microscope equipped with a motorized stage (Märzhäuser, Germany) with MosaiX software and by means of a CCD camera (Zeiss MRC) connected to an Axiovision 4.6 image analysis system (Zeiss, Germany).

Counts were performed using the optical fractionator method $[19,37]$ on a Zeiss Axioskop 2 plus microscope (Jena, Germany) equipped with a motorized stage (Märzhäuser, Wetzlar, Germany), a Ludl MAC 5000 controller (LEP, 


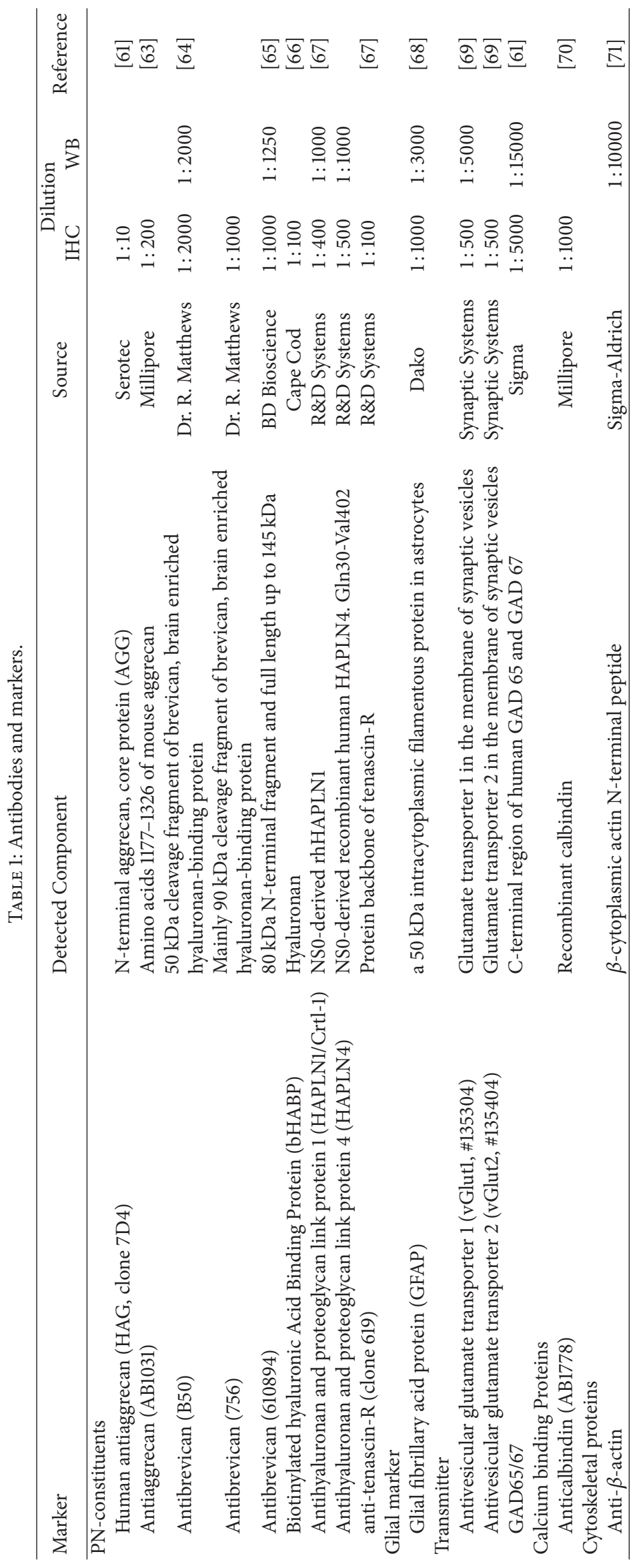


TABLE 2: Used secondary antibodies.

\begin{tabular}{lccc}
\hline Antibody & Marker & Dilution & Source \\
\hline Streptavidin & Cy3 & $1: 250$ & Dianova \\
Donkey-anti-mouse & Cy2, Cy3 & $1: 1000$ & Dianova \\
Donkey-anti-guinea pig & Cy3 & $1: 1000$ & Dianova \\
Donkey-anti-rabbit & Cy2, Cy3 & $1: 1000$ & Dianova \\
Donkey-anti-rabbit & HRP & $1: 10.000$ & DAKO \\
Donkey-anti-mouse & HRP & $1: 10.000$ & DAKO \\
Rabbit-anti-guinea pig & HRP & $1: 10.000$ & GE Healthcare \\
Rabbit-anti-goat & HRP & $1: 10.000$ & GE Healthcare \\
\hline
\end{tabular}

Hawthorne, NY, USA), and a digital camera CX9000 (MicroBrightField, Williston, VT, USA). Stereo Investigator software 6 (MicroBrightField, Williston, VT, USA) was used to analyze the $30 \mu \mathrm{m}$ thick sections.

The contours of the DCN were outlined in the Stereo Investigator program using a 10x lens, cell diameter determination and synapse counts were performed using an oilimmersion $63 x$ lens (1.4 numerical aperture).

Somatic boutons were counted from the cell surface of the large glutamatergic PN-bearing projection neurons $(\geq 10 \mu \mathrm{m}$ diameter) up to a distance of $3 \mu \mathrm{m}$ in the periphery. For quantification of the boutons in the periphery, the cells were outlined at a distance of twofold diameter of the cell from the cell surface. Peripheral boutons were counted from the end of the somatic zone $(\geq 3 \mu \mathrm{m})$ to the outlined area.

2.5. SDS-PAGE and Western Blot Analyses. Mice were deeply anesthetized with $\mathrm{CO}_{2}$, decapitated, brains rapidly removed, and immediately frozen in liquid nitrogen. On a dry-ice cooled work plate the brains were cut in $2 \mathrm{~mm}$ frontal sections and DCN as precise as possible separated and stored in $2 \mathrm{~mL}$ tubes at $-80^{\circ} \mathrm{C}$ until further proceeding. The DCN containing tissues of 5 mutant and $5 w t$ mice were homogenized using an Ultra-Turrax tube drive (IKA), in homogenization buffer $(20 \mathrm{mM}$ Tris- $\mathrm{HCl}, 2 \mathrm{mM}$ EDTA, $0.15 \mathrm{M} \mathrm{NaCl}, 5 \mathrm{mM} \mathrm{NaF}, 1 \mathrm{mM} \mathrm{Na}_{3} \mathrm{VO}_{4}$, and $2 \mathrm{mM} \mathrm{MgCl}_{2}$, $\mathrm{pH}$ 7.4) containing a protease inhibitor (Complete, Roche, Mannheim, Germany). The homogenate was centrifuged at $10.000 \times \mathrm{g}$ for $14 \mathrm{~min}$ at $4^{\circ} \mathrm{C}$, followed by determination of the protein concentration in the supernatant by using the BCA Assay. For discontinuous SDS-Page the supernatant containing $35 \mu \mathrm{g}$ proteins was mixed with 1x SDS sample buffer and denaturized at $70^{\circ} \mathrm{C}$ for $15 \mathrm{~min}$. The proteins were separated on a $10 \%$ polyacrylamide gel and transferred to a polyvinylidene difluoride membrane (Perkin Elmer, Rodgau, Germany). Blots were blocked with $1 \%$ BSA in Tris-buffered saline containing $0.05 \%$ tween for $1 \mathrm{~h}$, washed, and incubated with primary antibodies (Table 1) diluted in blocking solution overnight at $4^{\circ} \mathrm{C}$. Blots were washed and incubated with HRP-conjugated secondary antibodies (Table 2) for $1 \mathrm{~h}$. HRP activity was detected using ECL Western blotting (Amersham Biosciences) and scanned with DNR Bio-Imaging System and analyzed by using software TINA. The ratios of optical density of the investigated proteins were normalized to $\beta$-actin.
2.6. Statistical Analyses. Statistical analysis was performed with SigmaPlot 12.5 (Systat Software, Erkrath, Germany). Values are given as mean \pm SEM. For statistical differences between the two genotypes we used $t$-test or Mann-Whitney rank sum test, depending on the distribution of the data.

\section{Results}

The Purkinje cell degeneration $(p c d-3 \mathrm{j} / \mathrm{J})$ mutant mouse is characterized by the loss of PCs and their axons. The neurons of the DCN and lateral vestibular nucleus (LVN), which are innervated by the cerebellar PCs, are affected as well. In immunohistochemical and biochemical investigations, we observed that the degeneration leads to altered synaptic innervation and ECM conformation in the target areas.

3.1. Calbindin D-28k in pcd Mice. Calbindin D-28k is typically used as a marker for the PCs of the cerebellum [20]. The closely spaced somas and axons of the PCs are strongly labeled by antibodies against calbindin. In $p c d$ mice this calbindin immunoreaction is significantly reduced. Only very few remaining cells are stained already at one month of age (Figure 1).

3.2. Purkinje Cell Degeneration in the Cerebellum Leads to Reduced GABAergic and an Increase of Glutamatergic Synapses in DCN and LVN. Similar to DCN neurons the neurons of the LVN are highly innervated by the GABAergic Purkinje axons. In addition, they receive excitatory input from mossy fibers and climbing fibers [21]. Previous studies demonstrated that pcd is accompanied by a volume reduction and a decrease in cell number in the DCN and LVN with focusing onto inhibitory neurons [22, 73-75]. Thus, we studied if the degeneration of PCs in the cerebellar cortex modifies the terminating synapses of the afferent fibers at the large excitatory $\mathrm{PN}$-bearing projection neurons in the DCN and LVN. Therefore, we investigated the GABAergic terminals by anti-GAD65/67 antibody labeling and the majority of glutamatergic terminals labeled by a mixture of anti-vGlutl and 2 antibodies at the PN-ensheathed neurons. The different nuclei (DCN, LVN) show similar distribution of these markers. Hence, the data of the nuclei were pooled.

We could identify a high density of GABAergic terminals at the cell surface (up to $3 \mu \mathrm{m}$ distance) as well as in the periphery ( $\geq 3 \mu \mathrm{m}$; for details see Section 2$)$ of each PNbearing neuron. The number of GABAergic synapses at large $\mathrm{PN}$-ensheathed neurons of $p c d$ mice was significantly lower than in the $w t$ mice (Figures 2(a) and 3(a); somatic boutons: $w t: 17.34 \pm 0.58$ and $p c d: 10.27 \pm 0.41$; MannWhitney $U p<0.0001$; peripheral boutons: wt: $18.18 \pm$ 0.83; pcd: $10.44 \pm 0.55$; Mann-Whitney $U p<0.0001$ ). There were no differences between the densities of somatic versus peripheral GABAergic boutons in both genotypes. Western blot analyses of whole DCN tissue homogenates with anti-GAD65/67 antibody identified the typical molecular weight bands at 65 and $67 \mathrm{kDa}$, respectively, though the quantification of the GAD band of $w t$ and $p c d$ showed no 

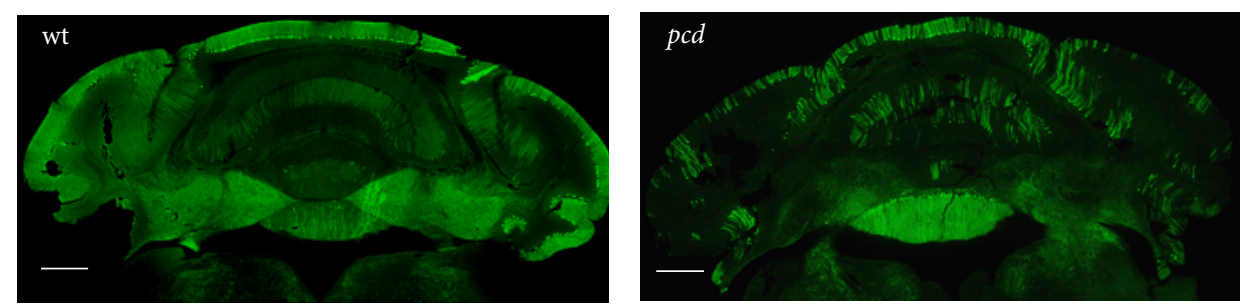

(a)
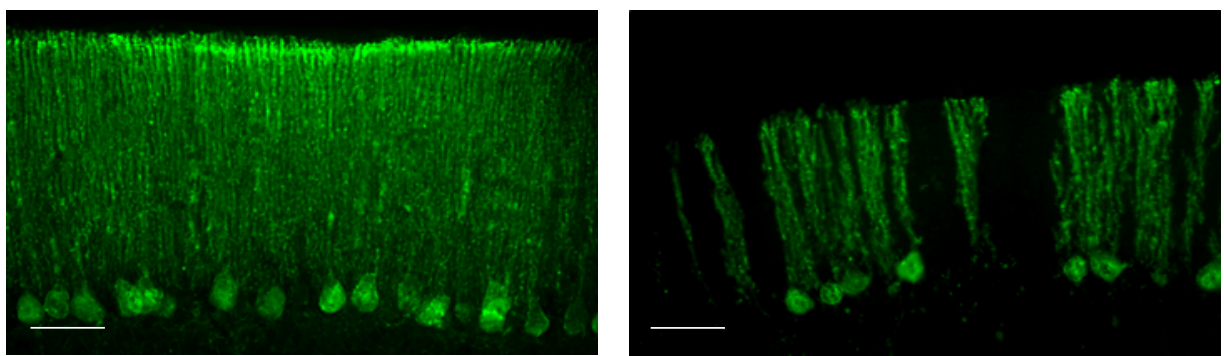

(b)

FIgURE 1: Labelling of calbindin expressing PC neurons in $w t$ and $p c d$ mice. Purkinje cells and their axons in the cerebellum show a strong immunoreactivity for calbindin. In one month old $w t$ anti-calbindin antibodies detect the Purkinje cells and their axon in the cerebellum. The neurons of the cerebellum in one-month-old $p c d$ mice reveal less calbindin immunoreactivity. Scale bar: $100 \mu \mathrm{m}$ (a) and $50 \mu \mathrm{m}$ (b).
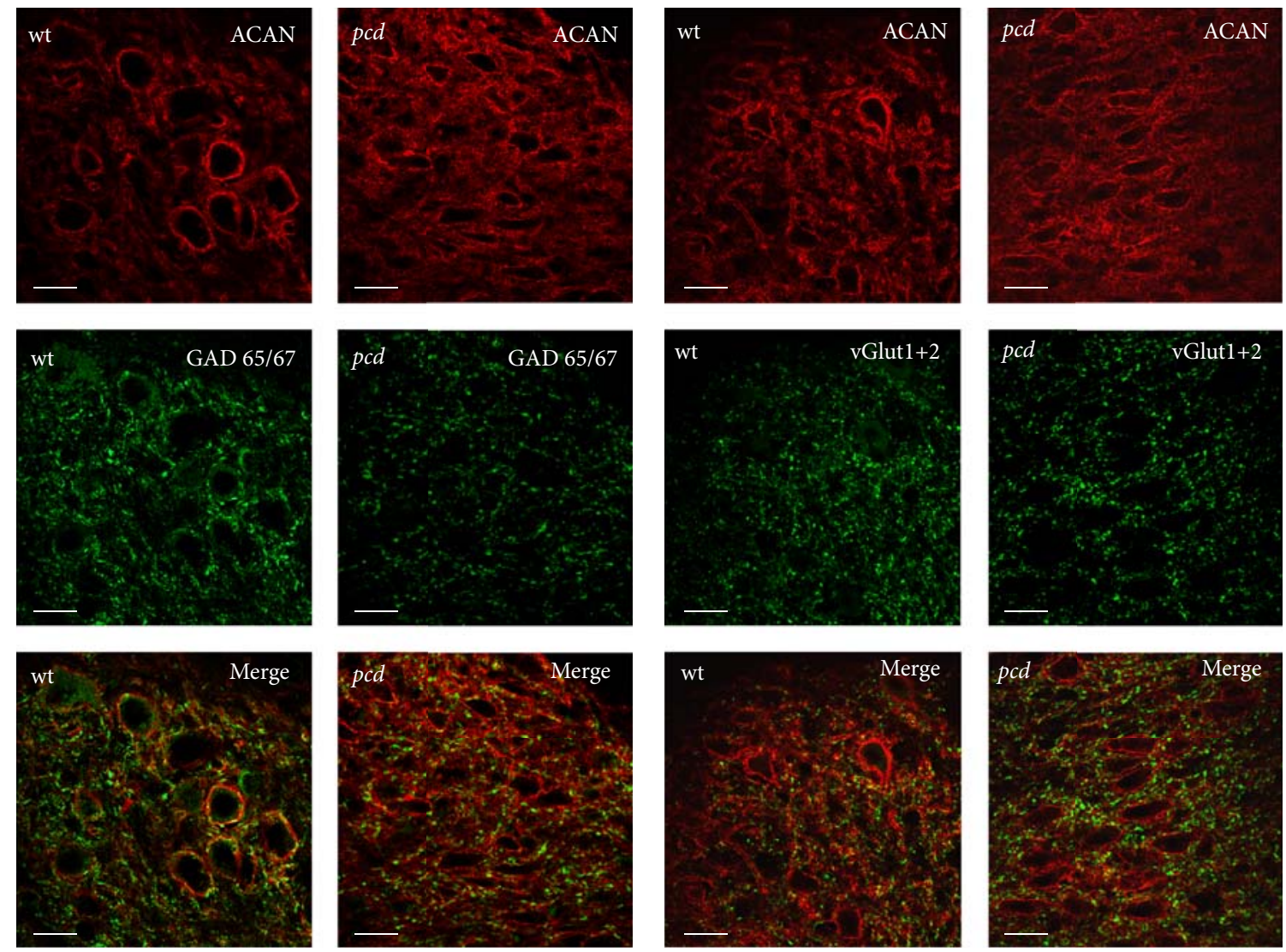

(a)

(b)

FIGURE 2: Detection of glutamatergic and GABAergic terminals in DCN. The large DCN neurons are enwrapped by aggrecan-based ECM (red). (a) DCN neurons are innervated by GABAergic boutons, labeled by GAD 65/67. GABAergic terminals seem to be reduced in $p c d$. (b) The glutamatergic boutons at DCN neurons are discovered by moderate vGlut 1 and vGlut 2 staining. The staining in pcd appears slightly enhanced. Scale bar: $20 \mu \mathrm{m}$. 


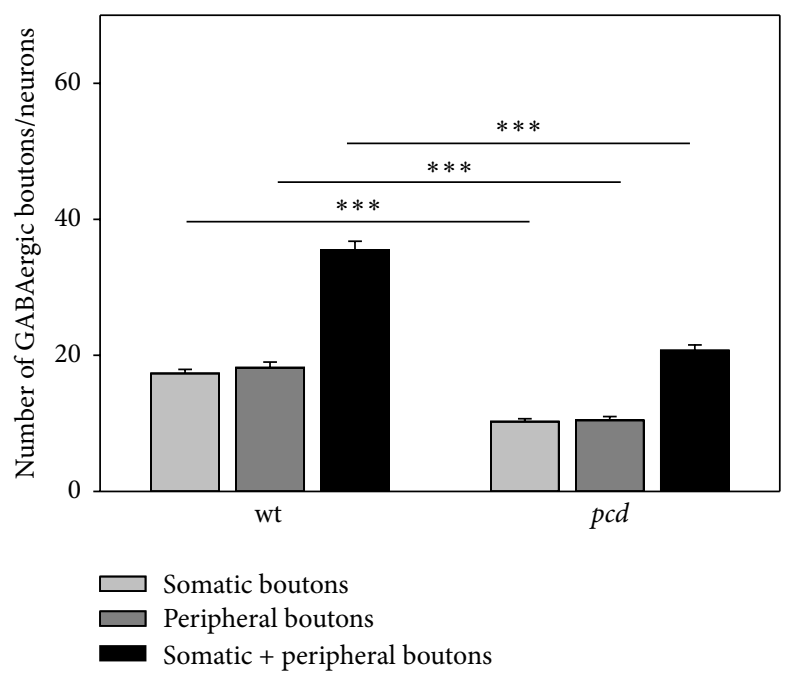

(a)

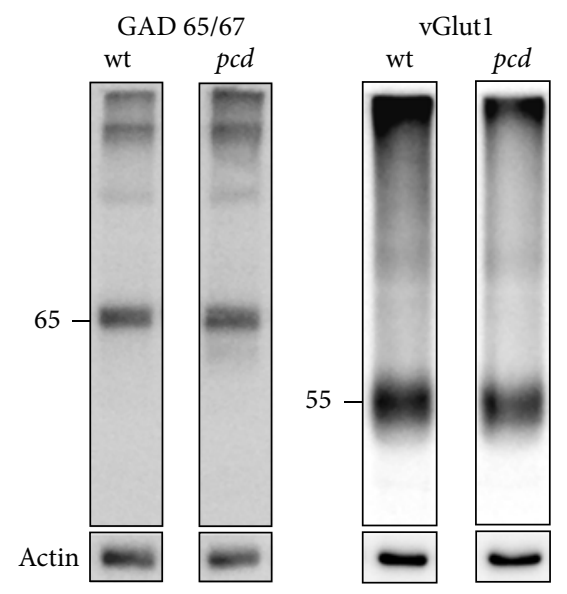

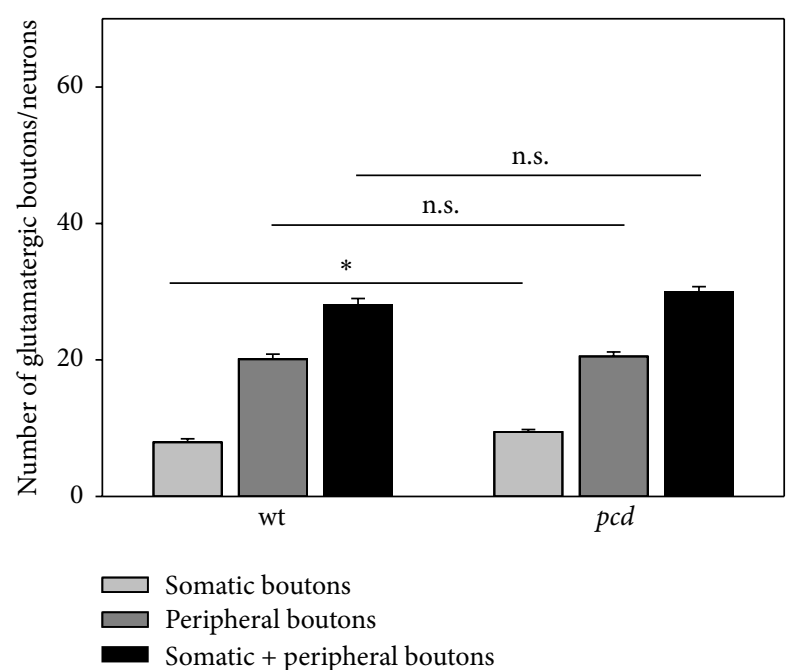

(b)

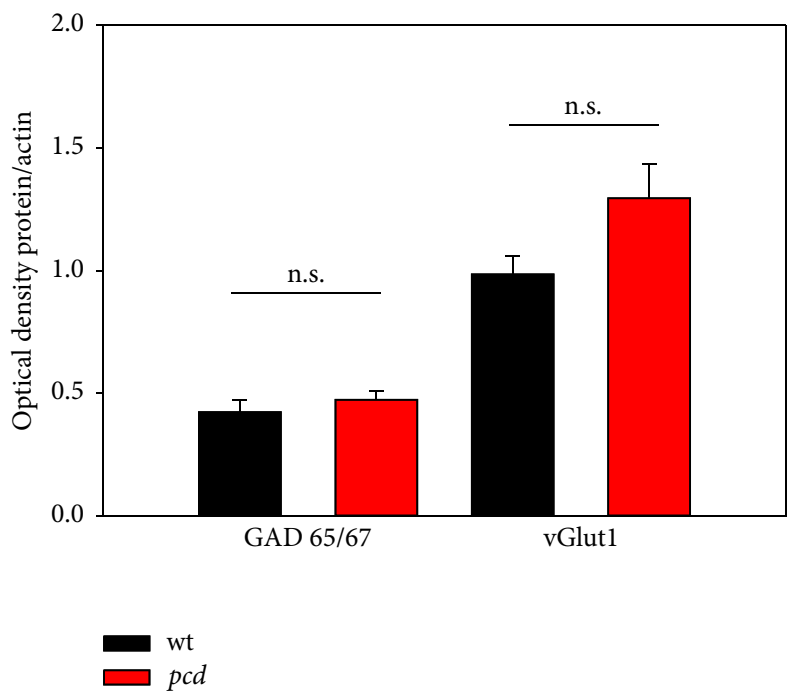

(c)

FIGURE 3: Quantification of GAD65/67 and vGlut in DCN. (a) Quantification shows the distribution of GABAergic terminals in different distances from the PN-bearing neurons. The total number of boutons are reduced in pcd compared to $w t$, regardless of the distance. (b) Somatic glutamatergic terminals at DCN neurons appear to be enhanced in $p c d$ mice. The peripheral synapses remain unaffected by the insult. (c) Western blot analyses of GAD65/67 and vGlut1 with protein extracts of DCN sections. Typical specific bands are visible in both genotypes. Quantification of these bands reveals slight but no significant differences between $w t$ and $p c d$ (GAD65/67 $p=0.419$; vGlut1 $p=0.087)$. Data are given as mean \pm SEM.

significant differences (Figure 3(c); wt: $0.423 \pm 0.05$ and $p c d$ : $0.473 \pm 0.03$ t-test $p=0.419)$.

Beside the inhibitory innervation, the DCN neurons receive excitatory glutamatergic input from collaterals from the mossy and climbing fibers $[21,76]$. Immunolabeling of the glutamatergic synapses at PN-bearing neurons reveals that the majority of glutamatergic boutons is not directly located at the soma of these neurons, but rather in their periphery, about $\geq 3 \mu \mathrm{m}$ away from the cell body. By quantification of somatic and peripheral terminals, we could verify the differences between somatic and peripheral density of the glutamatergic synaptic terminals (Figure 3(b)). The density of somatic glutamatergic synapses in DCN and LVN of $p c d$ mice is increased, while the number of peripheral terminals is not altered (Figures 2(b) and 3(b); somatic boutons: wt: $7.93 \pm 0.51$ and $p c d: 9.43 \pm 0.38$; Mann-Whitney $U p=0.010$; peripheral boutons: $w t: 20.08 \pm 0.77$; $p c d: 20.50 \pm 0.67$; MannWhitney $U p=0.084)$. In addition, the quantification of the $55 \mathrm{kDa}$ anti-vGlut1 immunoreactive band in western blot confirmed an increase of vGlut1 in pcd mice without reaching significance (Figure 3(c); wt: $0.985 \pm 0.07$ and pcd: $1.295 \pm$ 0.14 ; $t$-test $p=0.087)$.

3.3. ECM Composition in DCN of pcd Mutant Mice. The axons of the Purkinje cells are the sole output of the cerebellar cortex and innervate the neurons of the DCN. The DCN 
mainly contain 2 types of neurons: large excitatory and smaller inhibitory neurons [53, 77]. As previously described, the large neurons of the DCN are ensheathed by very prominent $\mathrm{PNs}[25,58]$. The DCN neurons in $w t$ mice express the major ECM components aggrecan, brevican, neurocan, tenascin-R, hyaluronan, and hapln [25].

3.3.1. Brevican. Recently it was shown that the proteoglycan brevican is enriched at perisynaptic sites and is suggested to be associated with synaptic molecules $[18,78]$. Brevican has a metalloproteinase specific cleavage site and can occur as 50 and $80 / 90 \mathrm{kDa}$ cleavage product and as full length protein of $145 \mathrm{kDa}$ with no chondroitin sulfate (CS) and the CSbearing variant of over $245 \mathrm{kDa}$ [14, 64]. We investigated the incidence of the cleavage products and the CS-free type of full-length brevican $p c d$ mice. For immunocytochemistry, three different antibodies against brevican were used: antibrevican (BD Bioscience, FL) which detects the full length and the cleavage products, anti-B50 detecting exclusively the $50 \mathrm{kDa}$ cleavage product of brevican and anti-B756, which detects mainly the $90 \mathrm{kDa}$ and the full length isoform. In $w t$ DCN immunostaining with all brevican antibodies clearly revealed an immunoreactivity around the large DCN neurons and illustrates the typical brevican-based PN structure surrounding soma and proximal dendrites. In $p c d$ mice the DCN neurons show only very weak anti-B50 immunoreaction. Neurons and dendrites are still surrounded by faint immunoreactivity, whereas neurons in nontarget areas of PC axons like the cochlear nucleus $(\mathrm{CN})$ are not affected and show the typical brevican-based PN structure (Figure 4(b)). The FL and B756 antibodies show similar intensities of immunoreactivity in the $p c d$ mice. In the DCN not only the neuronal surface is detected, but the whole extracellular space reveals a slight and uniform immunoreactivity. As mentioned above, the neurons of the $\mathrm{CN}$, as an internal reference, show no alterations in the immunoreactivity with FL and B756. The neurons and proximal dendrites still display the typical brevican-based PN structure in $p c d$ mice (Figures 4(a) and $4(c))$. To further clarify if the altered immunodetection of brevican in $p c d$ mice is caused by reduced protein expression we investigated the protein levels of full length and the $50 \mathrm{kDa}$ cleavage product of brevican by western blot analyses. Surprisingly, a significant increased protein level of brevican could be detected in both the full length as well as the $50 \mathrm{kDa}$ cleavage product in the DCN containing tissue of $p c d$ mice compared to $w t$ mice. The brevican protein amount in the $p c d$ mice almost reached a 2 -fold increase compared to $w t$ mice (Figure 4(d), BCAN: $w t: 0.599 \pm 0.04$ and $p c d$ : $1.180 \pm 0.06$; $t$-test $p<0.001)$.

3.3.2. Link Proteins. Link proteins are known to interact with hyaluronan and CSPGs and stabilize this connection. Hapln1 (Crtl-1) and hapln4 are the two link proteins which are associated with PNs and exclusively expressed by PNbearing neurons $[25,26,59]$. It is supposed that hapln1 is an important component in PN formation. The upregulation of hapln1 expression correlates with $\mathrm{PN}$ development and hapln1 deficient mice showed attenuated PNs [32].
The PN of the large excitatory DCN neurons of $w t$ mice is characterized by a strong aggrecan staining and a comparably intensive staining by hapln1. The labeling of both $\mathrm{PN}$-components, aggrecan and hapln1, is for the most part congruent and they seem to be colocalized. In pcd mice the detection of aggrecan and hapln1 is less intensive but still clearly present (Figure 5(a)). The immunoreactions of both components appear largely colocalized, although the immunoreactions appear to be redistributed away from the nets into the neuropil and extracellular space, which might be in agreement with immunoblot analyses revealing increased occurrence of hapln1 (Figure 5(c), hapln1: $w t: 4.164 \pm 0.6$ and $p c d: 8.165 \pm 0.6$; $t$-test $p=0.001$ ).

Hapln4 immunodetection also marks PN-bearing neurons in the DCN of $w t$ mice. The large DCN neurons are surrounded by delicate hapln 4 staining and the labeling is colocalized with the aggrecan immunoreaction. The DCN neurons of $p c d$ mice are immunopositive for aggrecan, but virtually no hapln4 immunoreaction is detectable (Figure 5(b)). In contrast, on western blots the hapln4 protein, in DCN enriched homogenate, is slightly significantly elevated (Figure 5(c), hapln4: $w t: 0.424 \pm 0.04$ and $p c d: 0.637 \pm$ 0.05 ; $t$-test $p=0.014$ ).

3.3.3. Hyaluronan and Tenascin-R. Hyaluronan is a very large linear polymer and is supposed to be the backbone of PNs. To visualize hyaluronan in the DCN we used biotinylated hyaluronan binding protein (HABP). Hyaluronan shows a ubiquitous distribution in the DCN of $w t$ and $p c d$, with a typical elevated reactivity around PN-bearing neurons, and colocates with aggrecan immunoreaction in PNs (Figure 6(a)). Immunolabeling with tenascin- $R$ reveals similar staining patterns in DCN of both genotypes and show no obvious differences between transgenic and $w t$ mice (Figure 6(b)).

3.4. Gliosis in DCN after Purkinje Cell Degeneration. Lesions and injuries are often followed by gliosis and an increased expression of glial proteins and strong formation of glial structures [79], which replace the degenerated tissue and lost cellular structures. The distribution of astrocytes and their expression level were analyzed with anti-GFAP antibodies, an astrocytic marker. The double immunolabeling with antiaggrecan showed that the $w t$ DCN bears only a few GFAP positive astrocytes. In $w t$ astrocytes only appear at the edge of the DCN, while the complete DCN of $p c d$ mice are marked by a massive glia invasion (Figure 7(a)). These results agreed with the enhanced expression level of GFAP in $p c d$ mice and support the assumption that the degeneration of the PCs leads to a strong gliosis in their target area (Figure 7(b), GFAP: $w t$ : $0.785 \pm 0.03$ and $p c d: 2.086 \pm 0.26$; Mann-Whitney $U p=$ $0.008)$.

\section{Discussion}

4.1. Synaptic Input. DCN and LVN neurons are the direct targets of the cerebellar Purkinje cell axons. After their degeneration at an age when nearly all PCs degenerated, the GABAergic terminals in the target regions are significantly 

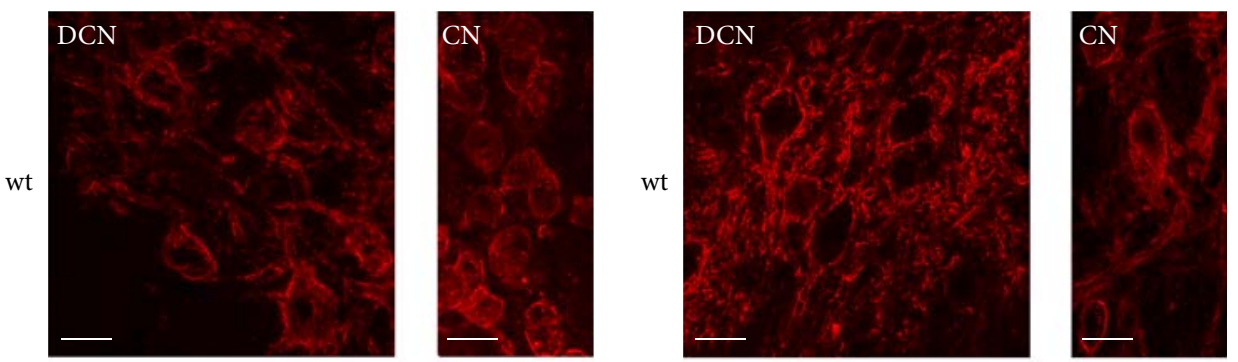

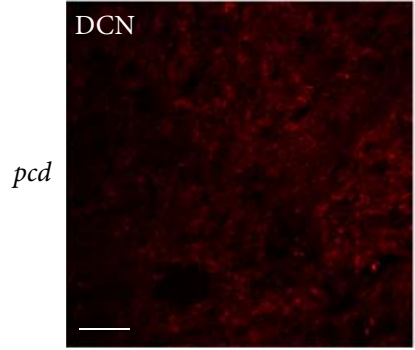

(a)

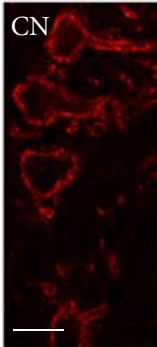

wt
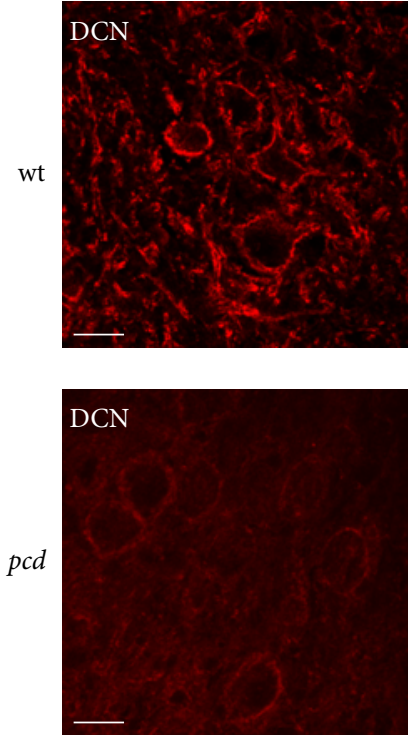

(c)
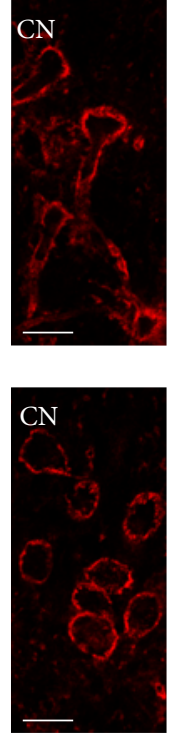

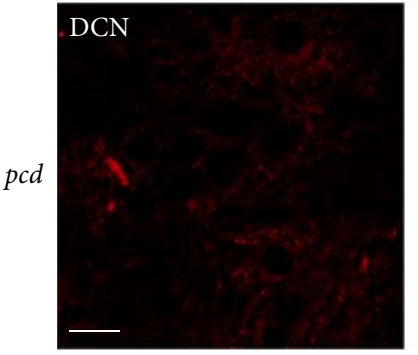

(b)

BCAN
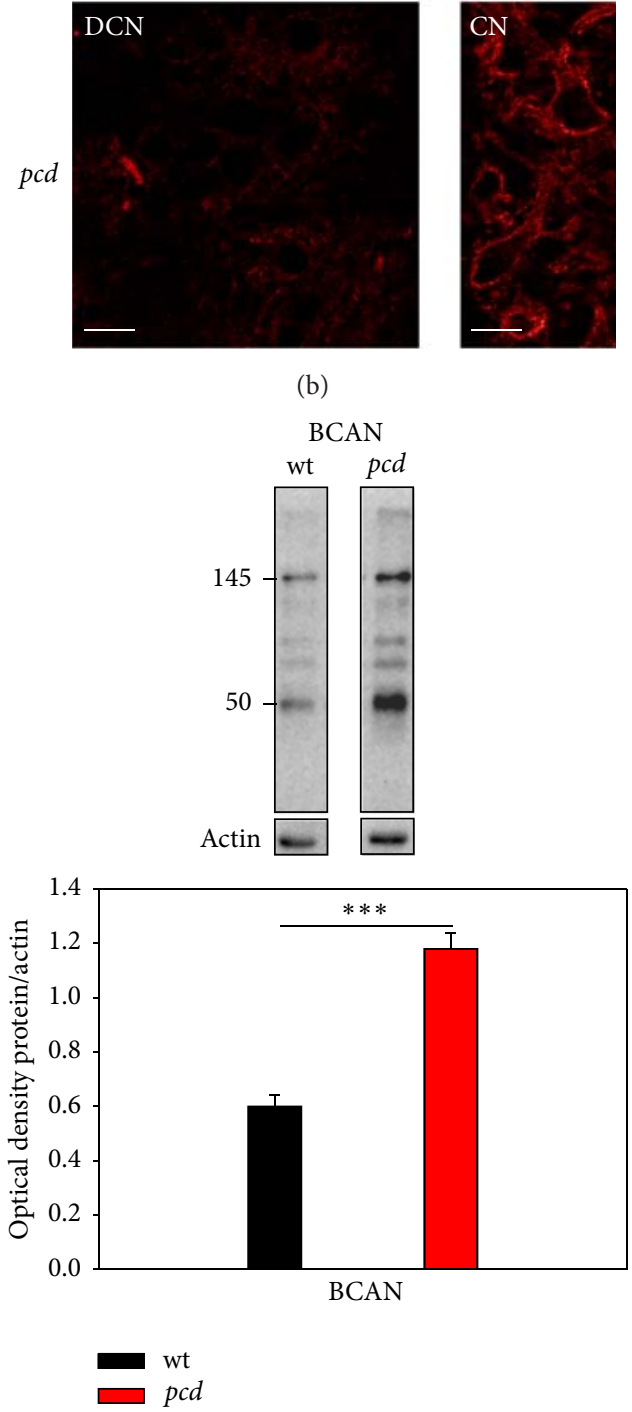

(d)

FIGURE 4: Detection of different brevican fragments. (a) Immunoreaction with pan-specific brevican antibodies (BD Bioscience, FL) clearly surrounds DCN neurons in $w t$ but not in $p c d$ mice. As internal control nontarget region of $\mathrm{PC}$ axons, the cochlear nucleus shows no alterations in immunoreactions with FL. (b) The $50 \mathrm{kDa}$ isoform of brevican seems to be nearly absent around DCN neurons of $p c d$ mice, whereas the not affected region $(\mathrm{CN})$ revealed brevican-bearing neurons. (c) The B756 antibodies detect mainly the 80/90 kDa and full length isoforms of brevican. These cleavage products aggregate around the neurons in DCN of $w t$ mice and seem to be integrated in PNs. In $p c d$, PNs appear with lower intensity, but with potential higher parenchymatic reaction. PN-detection with all three antibodies in the internal nontarget control region $(\mathrm{CN})$ is unchanged. Scale bar: $20 \mu \mathrm{m}$. (d) Biochemical detection of brevican with SDS-PAGE with pan-specific antibodies revealed most known isoforms at 50, 80, 90, and $145 \mathrm{kDa}$. Quantification of the 50 and $145 \mathrm{kDa}$ brevican isoform showed a significant increased protein expression in $p c d(p<0.001)$, respectively, for the different isoforms. Therefore, the diagram is supposed to display the optical density (OD) values of pan-brevican chemiluminescent signal summed values (OD $50 \mathrm{kDa}+145 \mathrm{kDa}$ brevican/actin). Data are given as mean \pm SEM. 

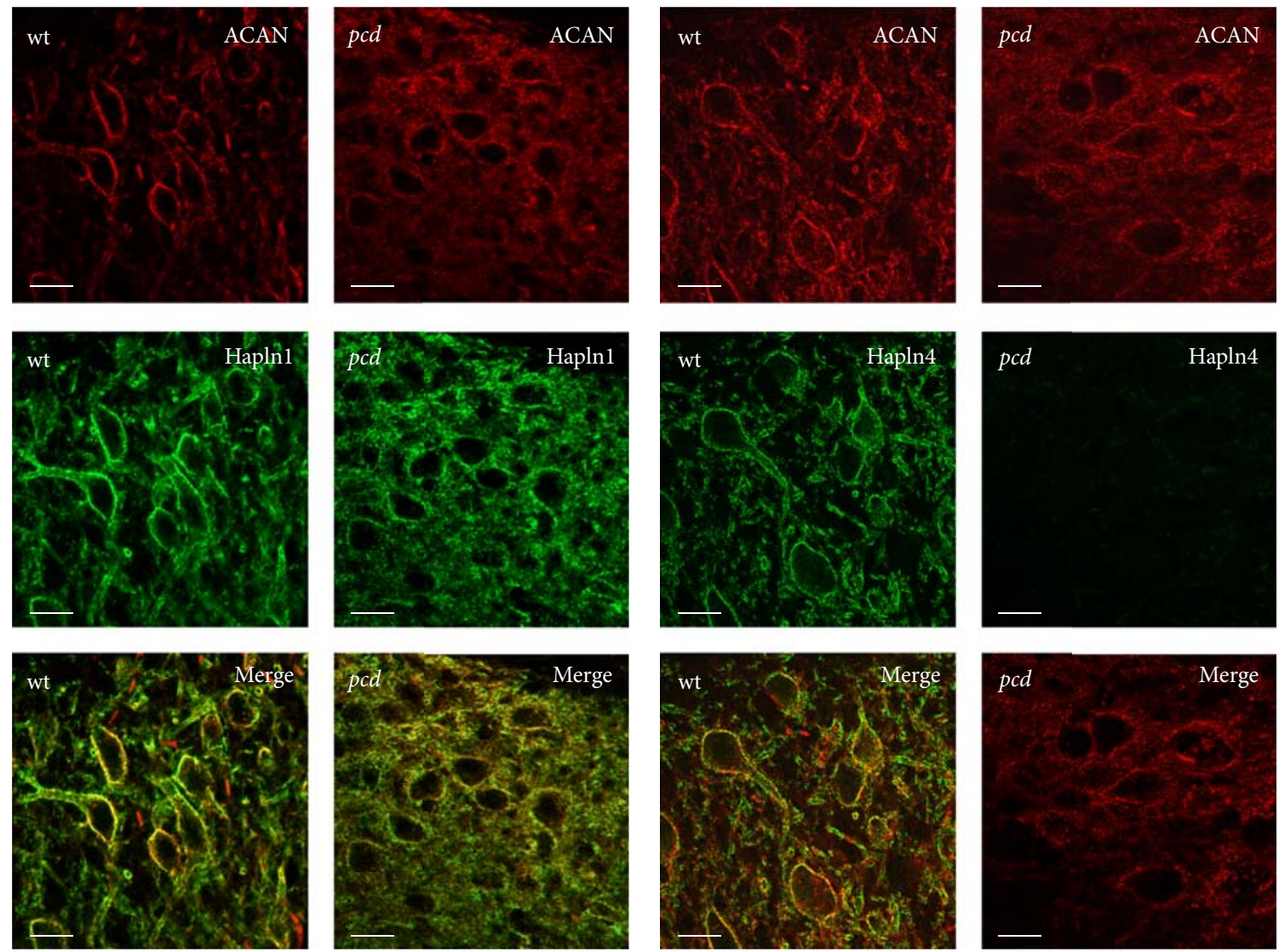

(a)

(b)
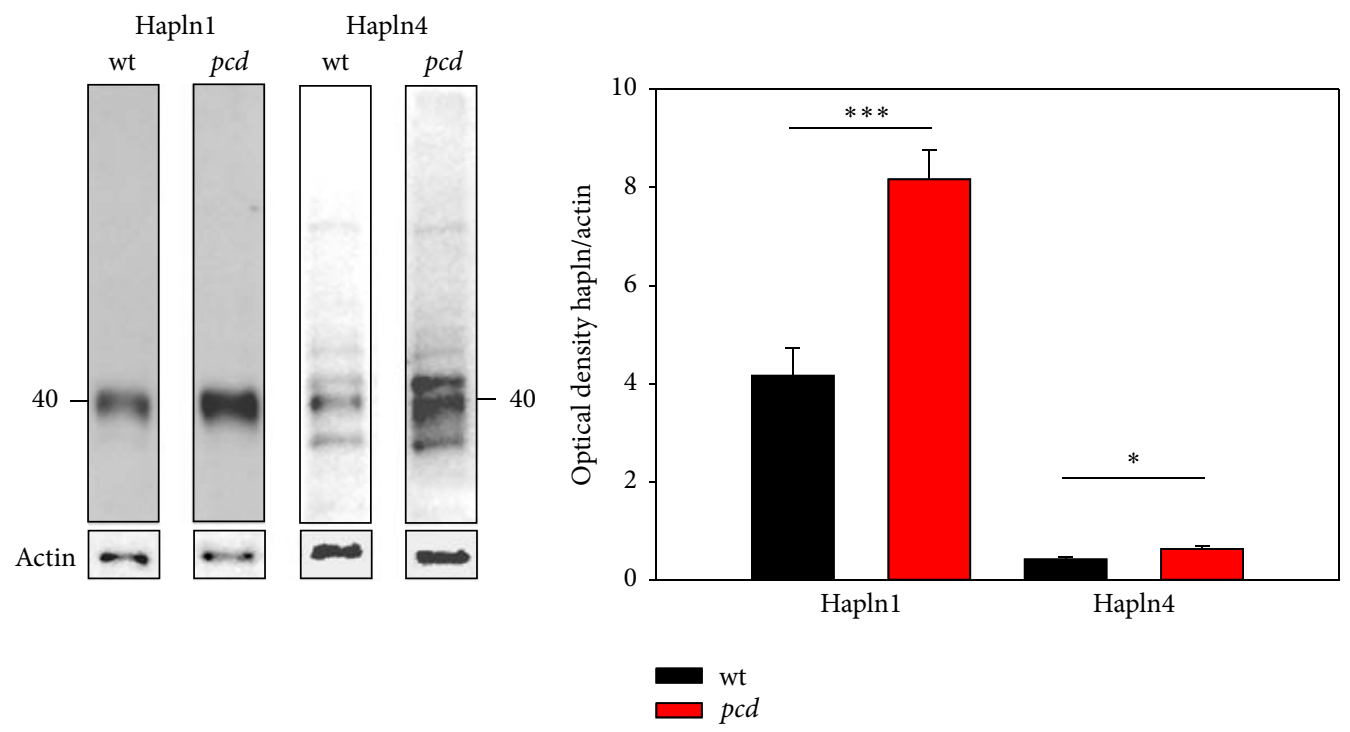

(c)

FIGURE 5: Comparison of link protein expression in DCN. DCN neurons are visualized by aggrecan immunoreaction (red). (a) Hapln1 labeling (green) surrounds the DCN neurons in both genotypes, matching the aggrecan immunoreactivity; additionally in $p c d$ hapln1 immunoreaction is distributed throughout the whole parenchyma. (b) Hapln4 (green) encloses the DCN neurons in wt mice. In contrast, hapln4 in pcd exhibits virtually no immunoreaction. Scale bar: $20 \mu \mathrm{m}$. (c) Western blot reveals protein bands at approximately $40 \mathrm{kDa}$ for link proteins. Quantification of the link proteins yielded an elevated protein level of both components in $p c d$ (hapln1 $p<0.01$; hapln $4 p<0.05$ ). Data are given as mean \pm SEM. 

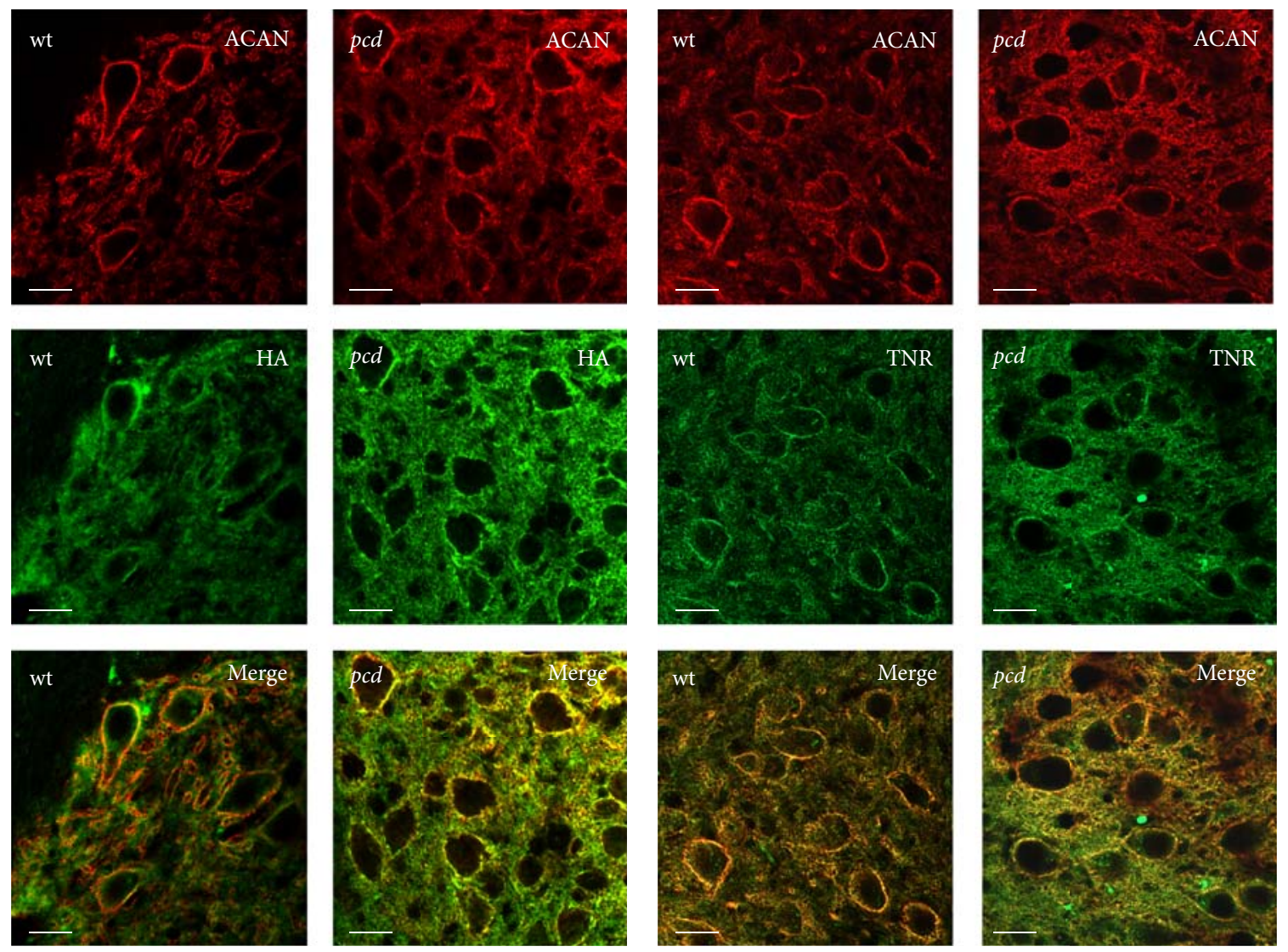

(a)
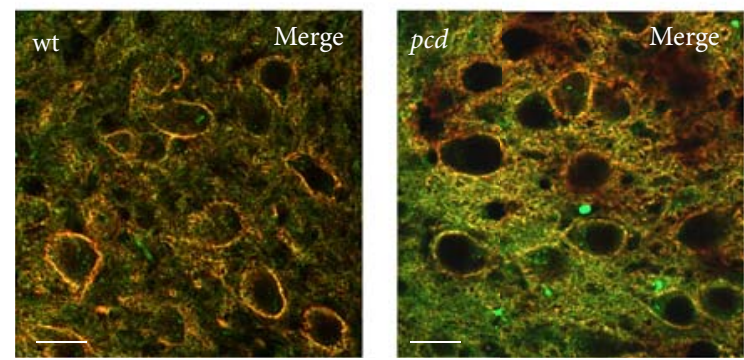

(b)

FIGURE 6: Distribution of hyaluronan and tenascin-R in DCN. The labeling shows important constituents of PNs. The neurons in DCN are surrounded by strong aggrecan immunoreaction (red). (a) Hyaluronan is ubiquitously distributed and concentrated around the neurons. (b) Tenascin-R is equally present in DCN of $w t$ and $p c d$ mice and mainly encloses the neurons. Scale bar: $20 \mu \mathrm{m}$.

reduced $[22,43,80]$. At PN-bearing neurons in DCN and LVN, a subset of large excitatory neurons, the GABAergic terminals are affected as shown by previous investigators [22, $80]$. Terminals at the PN-positive neurons are decrease down to $40 \%$ independent from terminal localization; somatic terminals as well as peripheral boutons are similarly reduced. In contrast, glutamatergic terminals are increased at $\mathrm{PN}$ bearing neurons after pcd. The degeneration of the PCs and the granule cells in the cerebellar cortex seems to result in a significant reorganization of the synaptic input (reviewed in [75]). Glutamatergic synapses in DCN mainly derive from mossy fibers, which additionally innervate granular cells in cerebellar cortex [81]. Strazielle et al. postulated for another $p c d$ model that the loss of Purkinje and granule cells leads to enhanced mossy fiber innervations at DCN neurons [82]. The $p c d-3 j / J$ model used in this study is also accompanied by an additional decline of cerebellar granule cells. Hence, a similar modification could take place in the DCN of the $p c d$ mice and might explain the increased glutamatergic innervations. The excitatory input of the LVN derives mainly from the fastigial nucleus of the DCN [83]; thus the enhanced glutamatergic projection in LVN might be a secondary effect of the lacking inhibition in the DCN neurons. The missing inhibitory innervation and the increased excitatory input might be interpreted as an altered activity of these neurons that could provide an explanation for the ataxic motion. However, in the $\mathrm{VN}$ of $p c d$ mutants neither the spontaneous activity nor the evoked activation of the neurons are altered $([84,85]$ reviewed in [75]). This is in agreement with the observation of axonal sprouting with flat vesicle terminals at the $p c d$ DCN neurons [80], which are known to represent inhibitory synapses [86]. The lost GABAergic contacts could be replaced by new non-GABAergic terminals. The massive gain and enhancement of glycinergic boutons observed in DCN and $\mathrm{VN}$ could maybe balance the deafferentation of GABAergic axons $[74,80]$. Glycine seems to play a predominant role in inhibition and modulates the excitation of DCN neurons; this could temper the symptomatology of the mutants.

4.2. Modifications in PN Formation after pcd. The large neurons in DCN are surrounded by PNs composed of hyaluronan, CSPGs, tenascin- $\mathrm{R}$, and link proteins hapln1 and hapln $4[25,59]$. Most of the PN-components are produced by neurons and several are synthetized by glia as well. Decline of Purkinje cells and consequently deafferentation of DCN 

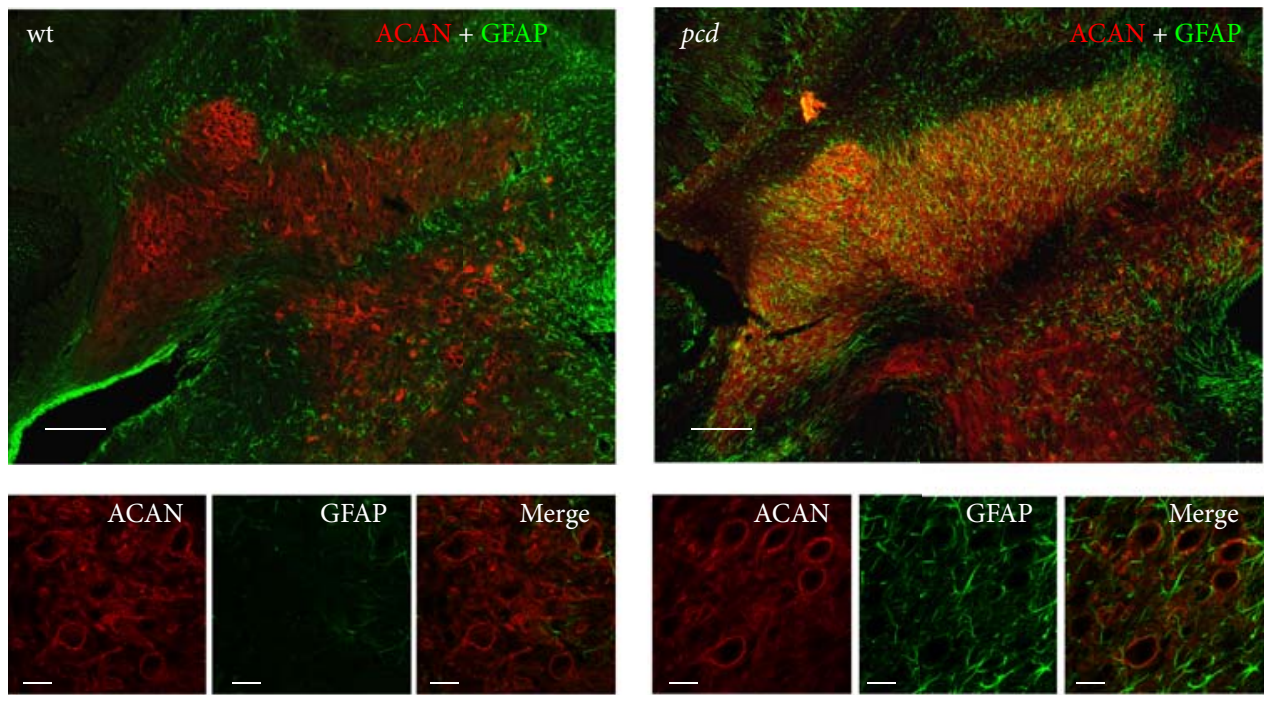

(a)

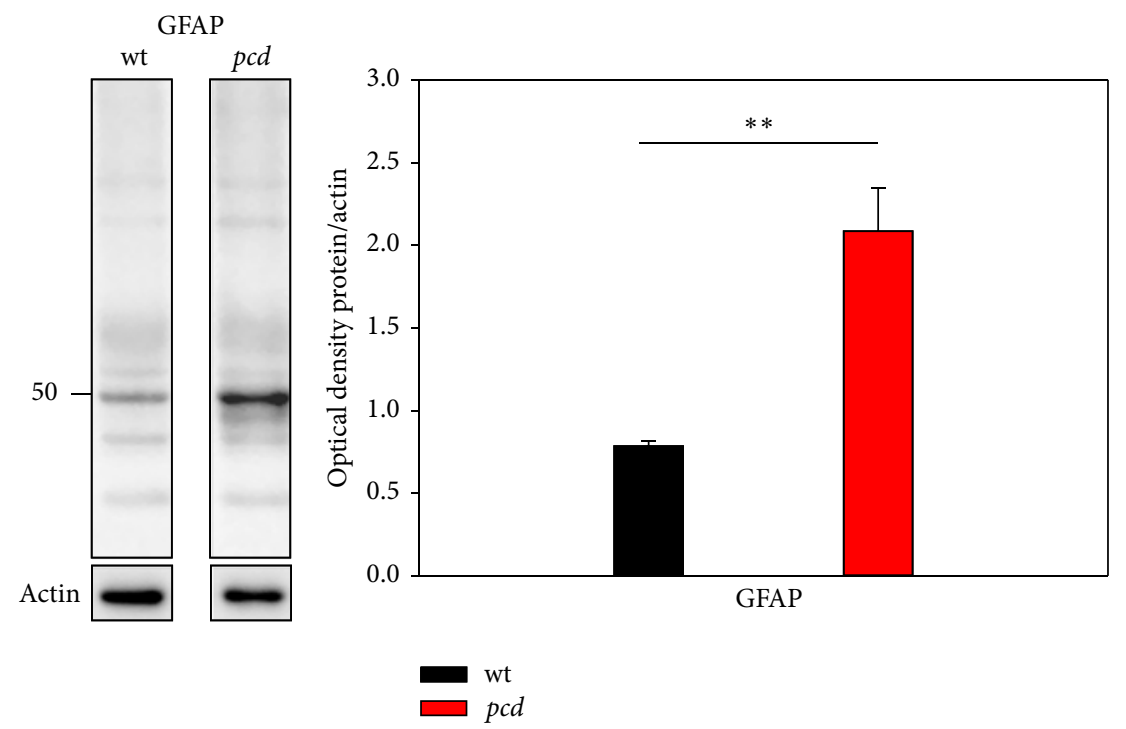

(b)

FIGURE 7: Reactive astrogliosis in the DCN of $p c d$ mouse brain. (a) DCN of $w t$ mouse brain is characterized by the virtual absence of reactive astrocytes. In $p c d$, the degeneration process is accompanied by a strong astrocytic activation; the DCN seem to be filled with astrocytes. Scale bar: overview $100 \mu \mathrm{m}$, detail $20 \mu \mathrm{m}$. (b) Western blot analyses confirm the immunocytochemical data. In $p c d$ tissue, the GFAP protein level is more than 2 -fold increased $(p<0.01)$. Data are given as mean \pm SEM.

neurons induce a significant reduction of certain $\mathrm{PN}$ components around the PC-target cells. PNs themselves are still present consisting of the main components hyaluronan, aggrecan, tenascin-R, and hapln1, but brevican and hapln 4 are apparently absent. That points to the assumption that brevican and hapln 4 are involved in synaptic stabilization and/or maintenance [78, 87]. Brevican is typically enriched at perisynaptic sites and is suggested to accumulate molecules necessary for synaptic formation and preservation $[14,18,87]$.

It has been reported that brevican expression is altered after brain injuries [15, 88, 89] and a loss of synapses is associated with a loss of brevican and hapln 4 or vice versa
$[8,87]$. In case of pcd the decay of cells and their axons in cerebellar cortex results in altered expression of brevican and hapln 4 in the DCN.

The fact that brevican and hapln 4 seem to be no longer an integral part of the PNs in the DCN of the pcd mice might confirm the assumption that they might be more sensitive to degeneration than the other PN-components and that both components seem to be strongly dependent on each other for integration into the PNs $[90,91]$. In early development, most CSPGs are more soluble and have only a low affinity to bind hyaluronan $[92,93]$. Link proteins play an important role in promoting the connection of CSPGs to hyaluronan by inducing conformation changes at the CSPGs allowing a 
strong interaction with hyaluronan $[59,94]$. Hapln 4 in the DCN is supposed to derive mainly from the PC axons $[25,59$, 87], so in $p c d$ mice the supply of the link protein is interrupted and potentially affects the localization of brevican [59].

\subsection{Enhanced Gliosis Determines Protein Properties. CNS} injury or degeneration processes are often combined with cell death leading to secretion of molecules triggering an extensive glial response and activation. The activation of different glial cells mostly follows a specific timeline. The first response to acute injuries is the migration of macrophages and microglia, followed by an activation of oligodendrocytes, and finalized with the proliferation of astrocytes [95]. While in the area of insult (cerebellar cortex) in $p c d$ mice an activation of microglia and astroglia was observed [96], this study identified that the DCN as a secondary affected area has rare microglia (IBA1 and S100b, data not shown) but extensive astrogliosis. Reactive astrocytes play an important role in regeneration by occupation of the vacated space, uptake of potentially excitotoxic glutamate, stabilization of extracellular fluid and ion balance, and protection from oxidative stress [97]. Beyond these functions, the expression of CSPGs in the injured brain is strongly upregulated due to astrocytes [98]. In regard to these findings several studies focused on brevican, which is expressed by reactive glia in response to brain injuries $[14,92,93,97,99-107]$. In the $p c d$ mice the SDS-PAGE also reveals an elevation of brevican in DCN after denervation. It is supposed that the cellular source of brevican can switch after injuries and is predominantly produced by astrocytes $[14,108]$. Brevican is sensitive to a number of matrix metalloproteinases (MMPs) and a disintegrin and metalloproteinase with a thrombospondin type 1 motif (ADAMTS) creating cleavage fragments of approximately $50 \mathrm{kDa}$ and $80 \mathrm{kDa}[64,109]$. In the adult and healthy brain, most MMPs are downregulated. After injuries the expression and enzymatic activity of MMPs and ADAMTS have been shown to be increased $[14,96,110-118]$ caused by activated glial cells $[118,119]$. MMP9 expression that is enhanced in the cerebellum of $p c d$ mice [96] is linked with the growthassociated protein GAP43 and promotes nerve regeneration and axonal sprouting $[4,120,121]$. The increased expression of the $50 \mathrm{kDa}$ cleavage fragment of brevican discovered in this study implies that there might be an increase of protease activity after degeneration in DCN contributing to extracellular matrix proteolysis, which is what loosens the PNs around the DCN neurons and facilitates new sprouting and synaptogenesis $[4,14,107,120]$.

It is not yet clarified if link proteins, which are mainly expressed by neurons, could also switch to glial expression after injury. In $p c d$ mice not only the nnal gene is disrupted, it is reported that the general gene transcription is downregulated $[122,123]$. Furthermore inflammatory events, which are known to be associated with degeneration, cause an increased methylation of the genomic region of hapln 4 and potentially decrease the neuronal gene expression $[93,124]$. The inhibited neuronal gene expression could promote a potential glial expression of hapln4. Sim et al. suggest that a glial hapln 4 expression leads to altered protein properties with a rather soluble nature [93]. However, it is supposed that the glial produced brevican is strongly associated with fibronectin which is highly enriched in cerebellum of $p c d$ mice [96] and modulates the cell adhesion and motility $[93,104]$ which may enable the reinnervation of PN-bearing DCN neurons. We speculate that the high amount of brevican could indeed stimulate the expression of the link protein, but hapln 4 has no binding partner anymore and cannot be robustly integrated into PNs.

4.4. Technical Consideration. Injuries, diseases, and degeneration-processes often lead to changes of PN-composition. It was reported that remodeling sometimes induces enhanced CSPG expression $[88,108,125,126]$, but it has also been shown that loss of synapses could be associated with reduced CSPG occurrence $[4,8,87]$. Our data display both reduction and enhancement of PN-constituents after degeneration. Deepa et al. [60] showed that detectability is strongly dependent on the solubility of the proteins and the used method. Immunohistochemical methods rather detect proteins in stable complexes and discover soluble fractions less efficiently. In contrast, pretreatment of the tissue for SDS-PAGE with special buffer releases most protein fraction, membrane associated, and soluble fractions [60]. The different techniques could lead to different but not contradictory results.

\section{Conclusions}

Degeneration of cerebellar Purkinje cells affects large PNbearing DCN neurons. The following events are an interplay of degeneration and regeneration. Not only the Purkinje cell derived GABAergic terminals decrease, but also the PNcomponents brevican and hapln 4 are virtually absent in the stable structure of the PNs of DCN neurons in pcd mice. Simultaneously, the hapln 4 and brevican protein expression is increased, probably caused by severe local inflammation processes with migrating astrocytes.

On one hand the attenuated PNs imply that brevican and/or hapln 4 are more sensitive to degeneration and might play a vital role in synaptic reorganization and the loss or variation of them might enable new sprouting of synapses. On the other hand, glial produced $\mathrm{PN}$-components reveal altered properties and could influence cell adhesion and motility to facilitate axonal path-finding.

\section{Conflict of Interests}

The authors declare that there is no conflict of interests regarding the publication of this paper.

\section{Authors' Contribution}

M. Blosa, C. Bursch, and M. Morawski contributed equally. 


\section{Acknowledgments}

The project was supported by the German Research Foundation (through Priority Program 1608; Mo2249/2-1), the EUCOST Action BM1001 "Brain Extracellular Matrix in Health and Disease", the Alzheimer Forschung Initiative e.V. (AFI \#11861), and the European Union and the Federal State of Saxony to Markus Morawski as well as the Institute Curie and the ANR-12-BSV2-0007 Grant to Carsten Janke.

\section{References}

[1] S. E. Arnold, "Neurodevelopmental abnormalities in schizophrenia: insights from neuropathology," Development and Psychopathology, vol. 11, no. 3, pp. 439-456, 1999.

[2] J. M. Shulman, P. L. de Jager, and M. B. Feany, "Parkinson's disease: genetics and pathogenesis," Annual Review of Pathology: Mechanisms of Disease, vol. 6, pp. 193-222, 2011.

[3] R. H. Swerdlow, "Pathogenesis of Alzheimer's disease," Clinical Interventions in Aging, vol. 2, no. 3, pp. 347-359, 2007.

[4] S. Foscarin, D. Ponchione, E. Pajaj et al., "Experience-dependent plasticity and modulation of growth regulatory molecules at central synapses," PLoS ONE, vol. 6, no. 1, Article ID e16666, 2011.

[5] A. Holtmaat and K. Svoboda, "Experience-dependent structural synaptic plasticity in the mammalian brain," Nature Reviews Neuroscience, vol. 10, no. 9, pp. 647-658, 2009.

[6] S. L. Florence, H. B. Taub, and J. H. Kaas, "Large-scale sprouting of cortical connections after peripheral injury in adult Macaque monkeys," Science, vol. 282, no. 5391, pp. 1117-1121, 1998.

[7] D. Carulli, S. Foscarin, A. Faralli, E. Pajaj, and F. Rossi, "Modulation of semaphorin3A in perineuronal nets during structural plasticity in the adult cerebellum," Molecular and Cellular Neuroscience, vol. 57, pp. 10-22, 2013.

[8] M. Morawski, G. Brückner, C. Jäger, G. Seeger, R. T. Matthews, and T. Arendt, "Involvement of perineuronal and perisynaptic extracellular matrix in Alzheimer's disease neuropathology," Brain Pathology, vol. 22, no. 4, pp. 547-561, 2012.

[9] H. Pantazopoulos, M. Markota, F. Jaquet et al., "Aggrecan and chondroitin-6-sulfate abnormalities in schizophrenia and bipolar disorder: a postmortem study on the amygdala," Translational Psychiatry, vol. 5, no. 1, article e496, 2015.

[10] P. V. Belichenko, J. Miklossy, B. Belser, H. Budka, and M. R. Celio, "Early destruction of the extracellular matrix around parvalbumin-immunoreactive interneurons in CreutzfeldtJakob disease," Neurobiology of Disease, vol. 6, no. 4, pp. 269$279,1999$.

[11] J. W. Fawcett, "The extracellular matrix in plasticity and regeneration after CNS injury and neurodegenerative disease," Progress in Brain Research, vol. 218, pp. 213-226, 2015.

[12] C. Hobohm, A. Günther, J. Grosche, S. Roßner, D. Schneider, and G. Brückner, "Decomposition and long-lasting downregulation of extracellular matrix in perineuronal nets induced by focal cerebral ischemia in rats," Journal of Neuroscience Research, vol. 80, no. 4, pp. 539-548, 2005.

[13] A. Suttkus, S. Rohn, S. Weigel, P. Glöckner, T. Arendt, and M. Morawski, "Aggrecan, link protein and tenascin-R are essential components of the perineuronal net to protect neurons against iron-induced oxidative stress," Cell Death and Disease, vol. 5, no. 3, Article ID el119, 2014.
[14] J. Mayer, M. G. Hamel, and P. E. Gottschall, "Evidence for proteolytic cleavage of brevican by the ADAMTSs in the dentate gyrus after excitotoxic lesion of the mouse entorhinal cortex," BMC Neuroscience, vol. 6, article 52, 2005.

[15] J. Aya-ay, J. Mayer, A. K. Eakin et al., "The effect of hypoxicischemic brain injury in perinatal rats on the abundance and proteolysis of brevican and NG2," Experimental Neurology, vol. 193, no. 1, pp. 149-162, 2005.

[16] G. Brückner, A. Bringmann, G. Köppe, W. Härtig, and K. Brauer, "In vivo and in vitro labelling of perineuronal nets in rat brain," Brain Research, vol. 720, no. 1-2, pp. 84-92, 1996.

[17] G. Brückner, J. Kacza, and J. Grosche, "Perineuronal nets characterized by vital labelling, confocal and electron microscopy in organotypic slice cultures of rat parietal cortex and hippocampus," Journal of Molecular Histology, vol. 35, no. 2, pp. 115-122, 2004.

[18] M. Blosa, M. Sonntag, G. Brückner et al., "Unique features of extracellular matrix in the mouse medial nucleus of trapezoid body-implications for physiological functions," Neuroscience, vol. 228, pp. 215-234, 2013.

[19] M. J. West, L. Slomianka, and H. J. G. Gundersen, "Unbiased stereological estimation of the total number of neurons in the subdivisions of the rat hippocampus using the optical fractionator," Anatomical Record, vol. 231, no. 4, pp. 482-497, 1991.

[20] M. R. Celio, "Calbindin D-28k and parvalbumin in the rat nervous system," Neuroscience, vol. 35, no. 2, pp. 375-475, 1990.

[21] M. Uusisaari and E. de Schutter, "The mysterious microcircuitry of the cerebellar nuclei," Journal of Physiology, vol. 589, no. 14, pp. 3441-3457, 2011.

[22] M. Wassef, J. Simons, M. L. Tappaz, and C. Sotelo, "NonPurkinje cell GABAergic innervation of the deep cerebellar nuclei: a quantitative immunocytochemical study in C57BL and in Purkinje cell degeneration mutant mice," Brain Research, vol. 399, no. 1, pp. 125-135, 1986.

[23] R. T. Matthews, G. M. Kelly, C. A. Zerillo, G. Gray, M. Tiemeyer, and S. Hockfield, "Aggrecan glycoforms contribute to the molecular heterogeneity of perineuronal nets," The Journal of Neuroscience, vol. 22, no. 17, pp. 7536-7547, 2002.

[24] C. M. Galtrey, J. C. F. Kwok, D. Carulli, K. E. Rhodes, and J. W. Fawcett, "Distribution and synthesis of extracellular matrix proteoglycans, hyaluronan, link proteins and tenascin- $\mathrm{R}$ in the rat spinal cord," European Journal of Neuroscience, vol. 27, no. 6, pp. 1373-1390, 2008.

[25] D. Carulli, K. E. Rhodes, D. J. Brown et al., "Composition of perineuronal nets in the adult rat cerebellum and the cellular origin of their components," Journal of Comparative Neurology, vol. 494, no. 4, pp. 559-577, 2006.

[26] S. Miyata, Y. Nishimura, N. Hayashi, and A. Oohira, "Construction of perineuronal net-like structure by cortical neurons in culture," Neuroscience, vol. 136, no. 1, pp. 95-104, 2005.

[27] T. Pizzorusso, P. Medini, N. Berardi, S. Chierzi, J. W. Fawcett, and L. Maffei, "Reactivation of ocular dominance plasticity in the adult visual cortex," Science, vol. 298, no. 5596, pp. 12481251, 2002.

[28] S. Hockfield, R. G. Kalb, S. Zaremba, and H. Fryer, "Expression of neural proteoglycans correlates with the acquisition of mature neuronal properties in the mammalian brain," Cold Spring Harbor Symposia on Quantitative Biology, vol. 55, pp. 505-514, 1990.

[29] G. Brückner, K. Brauer, W. Härtig et al., "Perineuronal nets provide a polyanionic, glia-associated form of microenvironment 
around certain neurons in many parts of the rat brain," Glia, vol. 8, no. 3, pp. 183-200, 1993.

[30] W. Härtig, A. Derouiche, K. Welt et al., "Cortical neurons immunoreactive for the potassium channel Kv3.1b subunit are predominantly surrounded by perineuronal nets presumed as a buffering system for cations," Brain Research, vol. 842, no. 1, pp. 15-29, 1999.

[31] A. Dityatev, G. Brückner, G. Dityateva, J. Grosche, R. Kleene, and M. Schachner, "Activity-dependent formation and functions of chondroitin sulfate-rich extracellular matrix of perineuronal nets," Developmental Neurobiology, vol. 67, no. 5, pp. 570$588,2007$.

[32] D. Carulli, T. Pizzorusso, J. C. F. Kwok et al., "Animals lacking link protein have attenuated perineuronal nets and persistent plasticity," Brain, vol. 133, no. 8, pp. 2331-2347, 2010.

[33] S. Foscarin, F. Rossi, and D. Carulli, "Influence of the environment on adult CNS plasticity and repair," Cell and Tissue Research, vol. 349, no. 1, pp. 161-167, 2012.

[34] R. G. Kalb and S. Hockfield, "Large diameter primary afferent input is required for expression of the Cat-301 proteoglycan on the surface of motor neurons," Neuroscience, vol. 34, no. 2, pp. 391-401, 1990.

[35] C. Lander, P. Kind, M. Maleski, and S. Hockfield, "A family of activity-dependent neuronal cell-surface chondroitin sulfate proteoglycans in cat visual cortex," The Journal of Neuroscience, vol. 17, no. 6, pp. 1928-1939, 1997.

[36] G. Brückner and J. Grosche, "Perineuronal nets show intrinsic patterns of extracellular matrix differentiation in organotypic slice cultures," Experimental Brain Research, vol. 136, no. 4, pp. 83-93, 2001.

[37] P. A. McRae, M. M. Rocco, G. Kelly, J. C. Brumberg, and R. T. Matthews, "Sensory deprivation alters aggrecan and perineuronal net expression in the mouse barrel cortex," Journal of Neuroscience, vol. 27, no. 20, pp. 5405-5413, 2007.

[38] A. Guimarães, S. Zaremba, and S. Hockfield, "Molecular and morphological changes in the cat lateral geniculate nucleus and visual cortex induced by visual deprivation are revealed by monoclonal antibodies Cat-304 and Cat-301," The Journal of Neuroscience, vol. 10, no. 9, pp. 3014-3024, 1990.

[39] E. S. Wintergerst, D. M. Vogt Weisenhorn, F. G. Rathjen, B. M. Riederer, S. Lambert, and M. R. Cello, “Temporal and spatial appearance of the membrane cytoskeleton and perineuronal nets in the rat neocortex," Neuroscience Letters, vol. 209, no. 3, pp. 173-176, 1996.

[40] N. P. Morris and Z. Henderson, "Perineuronal nets ensheath fast spiking, parvalbumin-immunoreactive neurons in the medial septum/diagonal band complex," European Journal of Neuroscience, vol. 12, no. 3, pp. 828-838, 2000.

[41] S. Reimers, M. Hartlage-Rübsamen, G. Brückner, and S. Roßner, "Formation of perineuronal nets in organotypic mouse brain slice cultures is independent of neuronal glutamatergic activity," European Journal of Neuroscience, vol. 25, no. 9, pp. 2640-2648, 2007.

[42] A. Harauzov, M. Spolidoro, G. DiCristo et al., "Reducing intracortical inhibition in the adult visual cortex promotes ocular dominance plasticity," Journal of Neuroscience, vol. 30, no. 1, pp. 361-371, 2010.

[43] R. J. Mullen, E. M. Eicher, and R. L. Sidman, "Purkinje cell degeneration, a new neurological mutation in the mouse," Proceedings of the National Academy of Sciences of the United States of America, vol. 73, no. 1, pp. 208-212, 1976.
[44] A. Fernandez-Gonzalez, A. R. La Spada, J. Treadaway et al., "Purkinje cell degeneration (pcd) phenotypes caused by mutations in the axotomy-induced gene, Nnal," Science, vol. 295, no. 5561, pp. 1904-1906, 2002.

[45] E. Kalinina, R. Biswas, I. Berezniuk, A. Hermoso, F. X. Aviles, and L. D. Fricker, "A novel subfamily of mouse cytosolic carboxypeptidases," The FASEB Journal, vol. 21, no. 3, pp. 836850, 2007.

[46] M. Rodriguez de La Vega, R. G. Sevilla, A. Hermoso et al., "Nnal-like proteins are active metallocarboxypeptidases of a new and diverse M14 subfamily," The FASEB Journal, vol. 21, no. 3, pp. 851-865, 2007.

[47] K. Rogowski, J. van Dijk, M. M. Magiera et al., "A family of protein-deglutamylating enzymes associated with neurodegeneration," Cell, vol. 143, no. 4, pp. 564-578, 2010.

[48] C. Janke, K. Rogowski, D. Wloga et al., "Tubulin polyglutamylase enzymes are members of the TTL domain protein family," Science, vol. 308, no. 5729, pp. 1758-1762, 2005.

[49] L. C. Triarhou, "Rate of neuronal fallout in a transsynaptic cerebellar model," Brain Research Bulletin, vol. 47, no. 3, pp. 219222, 1998.

[50] T. Wang and J. I. Morgan, "The Purkinje cell degeneration (pcd) mouse: an unexpected molecular link between neuronal degeneration and regeneration," Brain Research, vol. 1140, no. 1, pp. 26-40, 2007.

[51] L. Chakrabarti, J. Eng, N. Ivanov, G. A. Garden, and A. R. La Spada, "Autophagy activation and enhanced mitophagy characterize the Purkinje cells of pcd mice prior to neuronal death," Molecular Brain, vol. 2, no. 1, article 24, 2009.

[52] S. C. Landis and R. J. Mullen, "The development and degeneration of Purkinje cells in pcd mutant mice," Journal of Comparative Neurology, vol. 177, no. 1, pp. 125-143, 1978.

[53] V. Chan-Palay, Cerebellar Dentate Nucleus: Organization, Cytology and Transmitters, Springer, Berlin, Germany, 1977.

[54] S. Chen and D. E. Hillman, "Colocalization of neurotransmitters in the deep cerebellar nuclei," Journal of Neurocytology, vol. 22, no. 2, pp. 81-91, 1993.

[55] C. I. de Zeeuw and A. S. Berrebi, "Postsynaptic targets of Purkinje cell terminals in the cerebellar and vestibular nuclei of the rat," European Journal of Neuroscience, vol. 7, no. 11, pp. 2322-2333, 1995.

[56] B. J. Fredette and E. Mugnaini, "The GABAergic cerebelloolivary projection in the rat," Anatomy and Embryology, vol. 184, no. 3, pp. 225-243, 1991.

[57] T. M. Teune, J. van der Burg, C. I. de Zeeuw, J. Voogd, and T. J. H. Ruigrok, "Single purkinje cell can innervate multiple classes of projection neurons in the cerebellar nuclei of the rat: a light microscopic and ultrastructural triple-tracer study in the rat," Journal of Comparative Neurology, vol. 392, no. 2, pp. 164-178, 1998.

[58] G. Seeger, K. Brauer, W. Härtig, and G. Brückner, "Mapping of perineuronal nets in the rat brain stained by colloidal iron hydroxide histochemistry and lectin cytochemistry," Neuroscience, vol. 58, no. 2, pp. 371-388, 1994.

[59] Y. Bekku, W.-D. Su, S. Hirakawa et al., "Molecular cloning of Bral2, a novel brain-specific link protein, and immunohistochemical colocalization with brevican in perineuronal nets," Molecular and Cellular Neuroscience, vol. 24, no. 1, pp. 148-159, 2003.

[60] S. S. Deepa, D. Carulli, C. Galtrey et al., "Composition of perineuronal net extracellular matrix in rat brain: a different 
disaccharide composition for the net-associated proteoglycans," The Journal of Biological Chemistry, vol. 281, no. 26, pp. 1778917800, 2006.

[61] G. Brückner, M. Morawski, and T. Arendt, "Aggrecan-based extracellular matrix is an integral part of the human basal ganglia circuit," Neuroscience, vol. 151, no. 2, pp. 489-504, 2008.

[62] A. Suttkus, S. Rohn, C. Jäger, T. Arendt, and M. Morawski, "Neuroprotection against iron-induced cell death by perineuronal nets-an in vivo analysis of oxidative stress," American Journal of Neurodegenerative Disease, vol. 1, no. 2, pp. 122-129, 2012.

[63] G. Brückner, S. Szeöke, S. Pavlica, J. Grosche, and J. Kacza, "Axon initial segment ensheathed by extracellular matrix in perineuronal nets," Neuroscience, vol. 138, no. 2, pp. 365-375, 2006.

[64] R. T. Matthews, S. C. Gary, C. Zerillo et al., "Brain-enriched hyaluronan binding (BEHAB)/brevican cleavage in a glioma cell line is mediated by a disintegrin and metalloproteinase with thrombospondin motifs (ADAMTS) family member," The Journal of Biological Chemistry, vol. 275, no. 30, pp. 22695-22703, 2000.

[65] H. Yamada, B. Fredette, K. Shitara et al., "The brain chondroitin sulfate proteoglycan brevican associates with astrocytes ensheathing cerebellar glomeruli and inhibits neurite outgrowth from granule neurons," Journal of Neuroscience, vol. 17, no. 20, pp. 7784-7795, 1997.

[66] D. Cabulli, K. E. Rhodes, and J. W. Fawcett, "Upregulation of aggrecan, link protein 1, and hyaluronan synthases during formation of perineuronal nets in the rat cerebellum," Journal of Comparative Neurology, vol. 501, no. 1, pp. 83-94, 2007.

[67] Z.-C. Xiao, J. Taylor, D. Montag, G. Rougon, and M. Schachner, "Distinct effects of recombinant tenascin-R domains in neuronal cell functions and identification of the domain interacting with the neuronal recognition molecule F3/11," European Journal of Neuroscience, vol. 8, no. 4, pp. 766-782, 1996.

[68] K. Leroy, C. Duyckaerts, L. Bovekamp, O. Müller, B. H. Anderton, and J. P. Brion, "Increase of adenomatous polyposis coli immunoreactivity is a marker of reactive astrocytes in Alzheimer's disease and in other pathological conditions," Acta Neuropathologica, vol. 102, no. 1, pp. 1-10, 2001.

[69] S. Takamori, J. S. Rhec, C. Rosenmund, and R. Jahn, "Identification of a vesicular glutamate transporter that defines a glutamatergic phenotype in neurons," Nature, vol. 407, no. 6801, pp. 189-194, 2000.

[70] F. Di Cunto, S. Imarisio, E. Hirsch et al., "Defective neurogenesis in citron kinase knockout mice by altered cytokinesis and massive apoptosis," Neuron, vol. 28, no. 1, pp. 115-127, 2000.

[71] M. Gimona, J. Vandekerckhove, M. Goethals, M. Herzog, Z. Lando, and J. V. Small, " $\beta$-actin specific monoclonal antibody," Cell Motility and the Cytoskeleton, vol. 27, no. 2, pp. 108-116, 1994.

[72] G. Paxinos and K. B. J. Franklin, The Mouse Brain in Stereotaxic Coordinates, Academic Press, San Diego, Calif, USA, 2nd edition, 2001.

[73] L. C. Triarhou, J. Norton, and B. Ghetti, "Anterograde transsynaptic degeneration in the deep cerebellar nuclei of Purkinje cell degeneration (pcd) mutant mice," Experimental Brain Research, vol. 66 , no. 3, pp. 577-588, 1987.

[74] J. Bäurle and U. Grüsser-Cornehls, "Differential number of glycine- and GABA-immunopositive neurons and terminals in the deep cerebellar nuclei of normal and Purkinje cell degeneration mutant mice," Journal of Comparative Neurology, vol. 382, no. 4, pp. 443-458, 1997.

[75] U. Grüsser-Cornehls and J. Bäurle, "Mutant mice as a model for cerebellar ataxia," Progress in Neurobiology, vol. 63, no. 5, pp. 489-540, 2001.

[76] J. Voogd and M. Glickstein, "The anatomy of the cerebellum," Trends in Cognitive Sciences, vol. 2, no. 9, pp. 307-313, 1998.

[77] C. Batini, C. Compoint, C. Buisseret-Delmas, H. Daniel, and M. Guegan, "Cerebellar nuclei and the nucleocortical projections in the rat: retrograde tracing coupled to GABA and glutamate immunohistochemistry," Journal of Comparative Neurology, vol. 315, no. 1, pp. 74-84, 1992.

[78] R. Frischknecht and C. I. Seidenbecher, "Brevican: a key proteoglycan in the perisynaptic extracellular matrix of the brain," International Journal of Biochemistry and Cell Biology, vol. 44, no. 7, pp. 1051-1054, 2012.

[79] M. R. Turner, A. Cagnin, F. E. Turkheimer et al., "Evidence of widespread cerebral microglial activation in amyotrophic lateral sclerosis: an [11C](R)-PK11195 positron emission tomography study," Neurobiology of Disease, vol. 15, no. 3, pp. 601-609, 2004.

[80] S. Roffler-Tarlov, P. M. Beart, S. O'Gorman, and R. L. Sidman, "Neurochemical and morphological consequences of axon terminal degeneration in cerebellar deep nuclei of mice with inherited Purkinje cell degeneration," Brain Research, vol. 168, no. 1, pp. 75-95, 1979.

[81] M. Uusisaari and T. Knöpfel, "GABAergic synaptic communication in the GABAergic and non-GABAergic cells in the deep cerebellar nuclei," Neuroscience, vol. 156, no. 3, pp. 537-549, 2008.

[82] C. Strazielle, R. Lalonde, L. Riopel, M. I. Botez, and T. A. Reader, "Regional distribution of the 5-HT innervation in the brain of normal and lurcher mice as revealed by $\left[{ }^{3} \mathrm{H}\right]$ citalopram quantitative autoradiography," Journal of Chemical Neuroanatomy, vol. 10, no. 2, pp. 157-171, 1996.

[83] S. C. Carleton and M. B. Carpenter, "Afferent and efferent connections of the medial, inferior and lateral vestibular nuclei in the cat and monkey," Brain Research, vol. 278, no. 1-2, pp. 29$51,1983$.

[84] C. Helmchen, "Vestibular responses of nucleus vestibularis neurons in wild-type mice and PCD-mutant mice," Pflügers Archiv, vol. 405, supplement 2, p. R56, 1985.

[85] U. Grüsser-Cornehls, "Compensatory mechanisms at the level of the vestibular nuclei following post-natal degeneration of specific cerebellar cell classes and ablation of the cerebellum in mutant mice," in Post-Lesion Neural Plasticity, H. Flohr, Ed., pp. 431-442, Springer, Berlin, Germany, 1988.

[86] J. Hámori and J. Takács, “Two types of GABA-containing axon terminals in cerebellar glomeruli of cat: an immunogold-EM study," Experimental Brain Research, vol. 74, no. 3, pp. 471-479, 1989.

[87] Y. Bekku, M. Saito, M. Moser et al., "Bral2 is indispensable for the proper localization of brevican and the structural integrity of the perineuronal net in the brainstem and cerebellum," Journal of Comparative Neurology, vol. 520, no. 8, pp. 1721-1736, 2012.

[88] X. Tang, J. E. Davies, and S. J. A. Davies, "Changes in distribution, cell associations, and protein expression levels of NG2, neurocan, phosphacan, brevican, versican $\mathrm{v} 2$, and tenascin- $\mathrm{C}$ during acute to chronic maturation of spinal cord scar tissue," 
Journal of Neuroscience Research, vol. 71, no. 3, pp. 427-444, 2003.

[89] C. C. Leonardo, A. K. Eakin, J. M. Ajmo, and P. E. Gottschall, "Versican and brevican are expressed with distinct pathology in neonatal hypoxic-ischemic injury," Journal of Neuroscience Research, vol. 86, no. 5, pp. 1106-1114, 2008.

[90] A. J. Day and G. D. Prestwich, "Hyaluronan-binding proteins: tying up the giant," The Journal of Biological Chemistry, vol. 277, no. 7, pp. 4585-4588, 2002.

[91] M. Mörgelin, D. Heinegård, J. Engel, and M. Paulsson, “The cartilage proteoglycan aggregate: assembly through combined protein-carbohydrate and protein-protein interactions," Biophysical Chemistry, vol. 50, no. 1-2, pp. 113-128, 1994.

[92] M. S. Viapiano, R. T. Matthews, and S. Hockfield, "A novel membrane-associated glycovariant of BEHAB/brevican is upregulated during rat brain development and in a rat model of invasive glioma," Journal of Biological Chemistry, vol. 278, no. 35, pp. 33239-33247, 2003.

[93] H. Sim, B. Hu, and M. S. Viapiano, "Reduced expression of the hyaluronan and proteoglycan link proteins in malignant gliomas," The Journal of Biological Chemistry, vol. 284, no. 39, pp. 26547-26556, 2009.

[94] L. I. Melching and P. J. Roughley, "Studies on the interaction of newly secreted proteoglycan subunits with hyaluronate in human articular cartilage," Biochimica et Biophysica Acta, vol. 1035, no. 1, pp. 20-28, 1990.

[95] J. W. Fawcett and R. A. Asher, "The glial scar and central nervous system repair," Brain Research Bulletin, vol. 49, no. 6, pp. 377391, 1999.

[96] F. C. Baltanás, M. T. Berciano, J. Valero et al., "Differential glial activation during the degeneration of Purkinje cells and mitral cells in the PCD mutant mice," Glia, vol. 61, no. 2, pp. 254-272, 2013.

[97] N. Thon, C. A. Haas, U. Rauch et al., "The chondroitin sulphate proteoglycan brevican is upregulated by astrocytes after entorhinal cortex lesions in adult rats," European Journal of Neuroscience, vol. 12, no. 7, pp. 2547-2558, 2000.

[98] J. Silver and J. H. Miller, "Regeneration beyond the glial scar," Nature Reviews Neuroscience, vol. 5, no. 2, pp. 146-156, 2004.

[99] D. M. Jaworski, G. M. Kelly, J. M. Piepmeier, and S. Hockfield, "BEHAB (brain enriched hyaluronan binding) is expressed in surgical samples of glioma and in intracranial grafts of invasive glioma cell lines," Cancer Research, vol. 56, no. 10, pp. 22932298, 1996.

[100] D. M. Jaworski, G. M. Kelly, and S. Hockfield, "Intracranial injury acutely induces the expression of the secreted isoform of the CNS-specific hyaluronan-binding protein BEHAB/brevican," Experimental Neurology, vol. 157, no. 2, pp. 327-337, 1999.

[101] C. A. Dwyer, W. L. Bi, M. S. Viapiano, and R. T. Matthews, "Brevican knockdown reduces late-stage glioma tumor aggressiveness," Journal of Neuro-Oncology, vol. 120, no. 1, pp. 63-72, 2014.

[102] B. Hu, L. L. Kong, R. T. Matthews, and M. S. Viapiano, “The proteoglycan brevican binds to fibronectin after proteolytic cleavage and promotes glioma cell motility," The Journal of Biological Chemistry, vol. 283, no. 36, pp. 24848-24859, 2008.

[103] S. C. Gary and S. Hockfield, "BEHAB/brevican: an extracellular matrix component associated with invasive glioma," Clinical Neurosurgery, vol. 47, pp. 72-82, 2000.
[104] R. Lu, C. Wu, L. Guo et al., "The role of brevican in glioma: promoting tumor cell motility in vitro and in vivo," $B M C$ Cancer, vol. 12, article 607, 2012.

[105] C.-L. Tso, P. Shintaku, J. Chen et al., "Primary glioblastomas express mesenchymal stem-like properties," Molecular Cancer Research, vol. 4, no. 9, pp. 607-619, 2006.

[106] M. S. Viapiano, W. L. Bi, J. Piepmeier, S. Hockfield, and R. T. Matthews, "Novel tumor-specific isoforms of BEHAB/brevican identified in human malignant gliomas," Cancer Research, vol. 65, no. 15, pp. 6726-6733, 2005.

[107] W. Yuan, R. T. Matthews, J. D. Sandy, and P. E. Gottschall, "Association between protease-specific proteolytic cleavage of brevican and synaptic loss in the dentate gyrus of kainatetreated rats," Neuroscience, vol. 114, no. 4, pp. 1091-1101, 2002.

[108] A. T. Beggah, M. T. Dours-Zimmermann, F. M. Barras, A. Brosius, D. R. Zimmermann, and A. D. Zurn, "Lesion-induced differential expression and cell association of Neurocan, Brevican, Versican V1 and V2 in the mouse dorsal root entry zone," Neuroscience, vol. 133, no. 3, pp. 749-762, 2005.

[109] H. Nakamura, Y. Fujii, I. Inoki et al., "Brevican is degraded by matrix metalloproteinases and aggrecanase-1 (ADAMTS4) at different sites," Journal of Biological Chemistry, vol. 275, no. 49, pp. 38885-38890, 2000.

[110] E. H. Lo, T. Dalkara, and M. A. Moskowitz, "Mechanisms, challenges and opportunities in stroke," Nature Reviews Neuroscience, vol. 4, no. 5, pp. 399-415, 2003.

[111] P. E. Gottschall and S. Deb, "Regulation of matrix metalloproteinase expression in astrocytes, microglia and neurons," NeuroImmunoModulation, vol. 3, no. 2-3, pp. 69-75, 1996.

[112] V. W. Yong, C. A. Krekoski, P. A. Forsyth, R. Bell, and D. R. Edwards, "Matrix and diseases of the CNS," Trends in Neurosciences, vol. 21, no. 2, pp. 75-80, 1998.

[113] A. Szklarczyk, J. Lapinska, M. Rylski, R. D. G. McKay, and L. Kaczmarek, "Matrix metalloproteinase-9 undergoes expression and activation during dendritic remodeling in adult hippocampus," Journal of Neuroscience, vol. 22, no. 3, pp. 920-930, 2002.

[114] J. W. Zhang, S. Deb, and P. E. Gottschall, "Regional and agerelated expression of gelatinases in the brains of young and old rats after treatment with kainic acid," Neuroscience Letters, vol. 295, no. 1-2, pp. 9-12, 2000.

[115] J. Jourquin, E. Tremblay, N. Décanis et al., "Neuronal activitydependent increase of net matrix metalloproteinase activity is associated with MMP-9 neurotoxicity after kainate," European Journal of Neuroscience, vol. 18, no. 6, pp. 1507-1517, 2003.

[116] L. Kaczmarek, J. Lapinska-Dzwonek, and S. Szymczak, "Matrix metalloproteinases in the adult brain physiology: a link between c-Fos, AP-1 and remodeling of neuronal connections?" The EMBO Journal, vol. 21, no. 24, pp. 6643-6648, 2002.

[117] H. J. Kim, H. L. Fillmore, T. M. Reeves, and L. L. Phillips, "Elevation of hippocampal MMP-3 expression and activity during trauma-induced synaptogenesis," Experimental Neurology, vol. 192, no. 1, pp. 60-72, 2005.

[118] R. Tauchi, S. Imagama, T. Natori et al., "The endogenous proteoglycan-degrading enzyme ADAMTS-4 promotes functional recovery after spinal cord injury," Journal of Neuroinflammation, vol. 9, article 53, 2012.

[119] E. M. Muir, K. H. Adcock, D. A. Morgenstern et al., "Matrix metalloproteases and their inhibitors are produced by overlapping populations of activated astrocytes," Molecular Brain Research, vol. 100, no. 1-2, pp. 103-117, 2002. 
[120] T. M. Reeves, M. L. Prins, J. Zhu, J. T. Povlishock, and L. L. Phillips, "Matrix metalloproteinase inhibition alters functional and structural correlates of deafferentation-induced sprouting in the dentate gyrus," The Journal of Neuroscience, vol. 23, no. 32, pp. 10182-10189, 2003.

[121] V. I. Shubayev and R. R. Myers, "Matrix metalloproteinase-9 promotes nerve growth factor-induced neurite elongation but not new sprout formation in vitro," Journal of Neuroscience Research, vol. 77, no. 2, pp. 229-239, 2004.

[122] F. C. Baltanás, I. Casafont, E. Weruaga, J. R. Alonso, M. T. Berciano, and M. Lafarga, "Nucleolar disruption and cajal body disassembly are nuclear hallmarks of DNA damage-induced neurodegeneration in Purkinje cells," Brain Pathology, vol. 21, no. 4, pp. 374-388, 2011.

[123] F. C. Baltanás, I. Casafont, V. Lafarga et al., "Purkinje cell degeneration in pcd mice reveals large scale chromatin reorganization and gene silencing linked to defective DNA repair," The Journal of Biological Chemistry, vol. 286, no. 32, pp. 28287-28302, 2011.

[124] M. A. Hahn, T. Hahn, D.-H. Lee et al., "Methylation of polycomb target genes in intestinal cancer is mediated by inflammation," Cancer Research, vol. 68, no. 24, pp. 1028010289, 2008.

[125] S. R. Saroja, A. Sase, S. G. Kircher et al., "Hippocampal proteoglycans brevican and versican are linked to spatial memory of Sprague-Dawley rats in the morris water maze," Journal of Neurochemistry, vol. 130, no. 6, pp. 797-804, 2014.

[126] G. Vinukonda, M. T. Zia, B. B. R. Bhimavarapu et al., "Intraventricular hemorrhage induces deposition of proteoglycans in premature rabbits, but their in vivo degradation with chondroitinase does not restore myelination, ventricle size and neurological recovery," Experimental Neurology, vol. 247, pp. 630-644, 2013. 

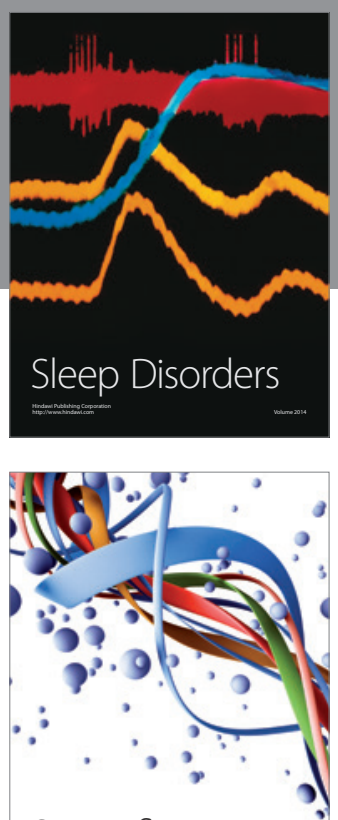

Scientifica
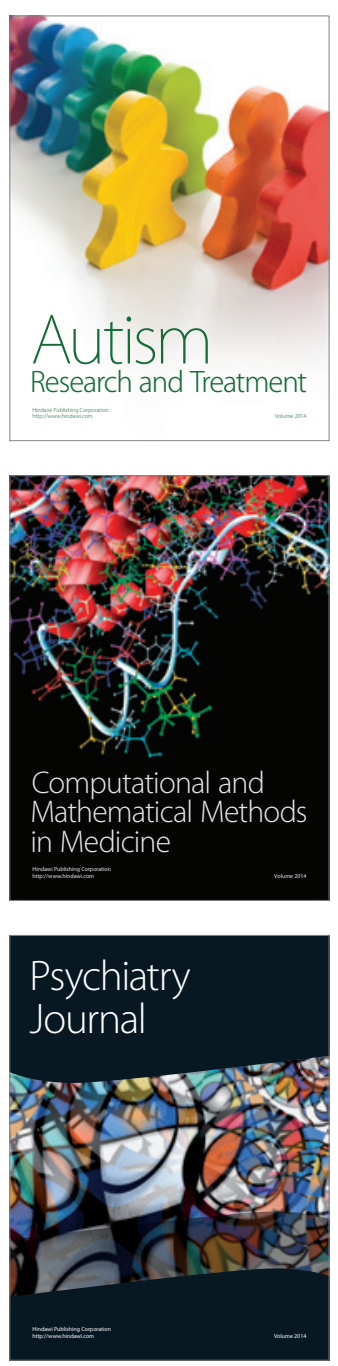
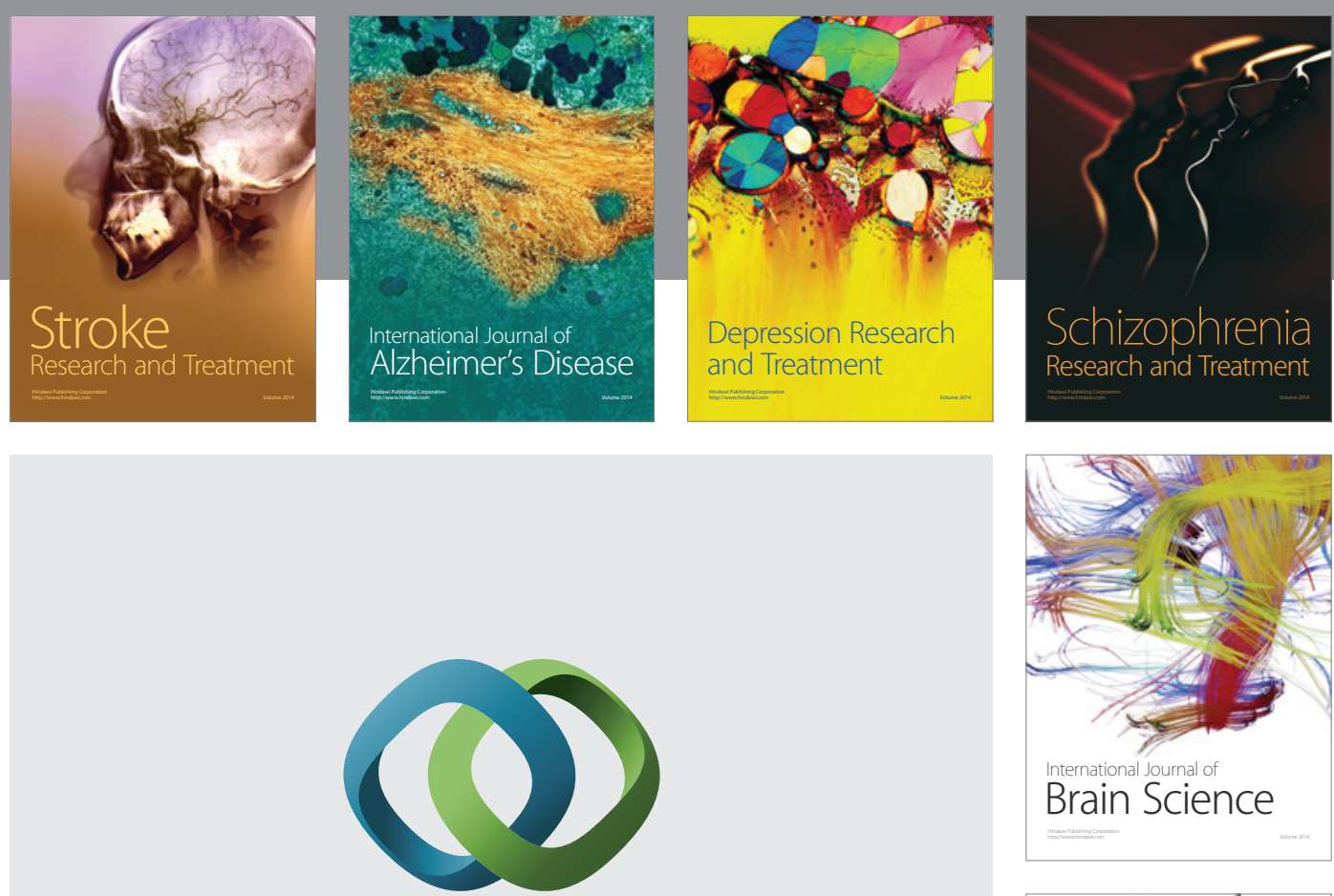

\section{Hindawi}

Submit your manuscripts at

http://www.hindawi.com
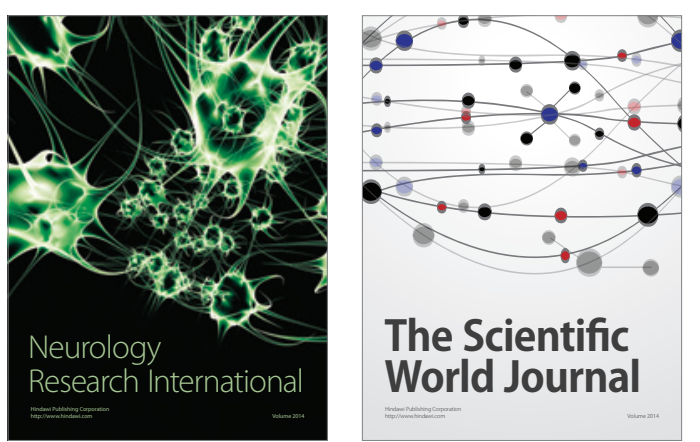

The Scientific World Journal

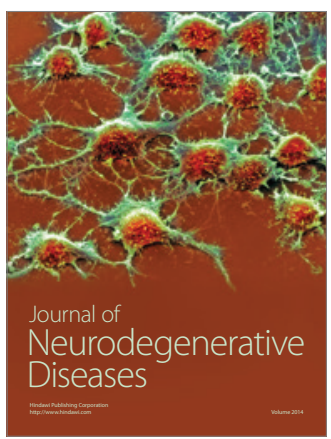

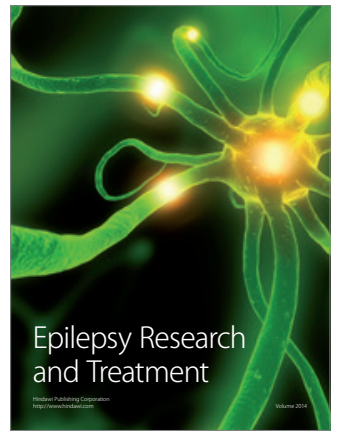

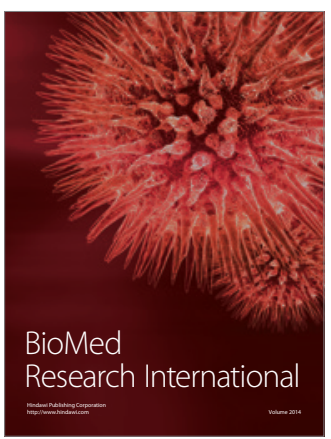

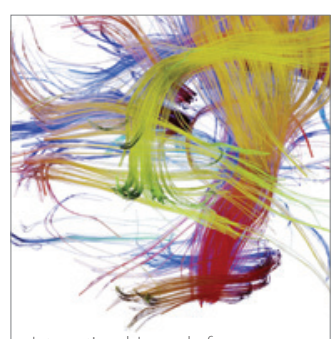

Brain Science

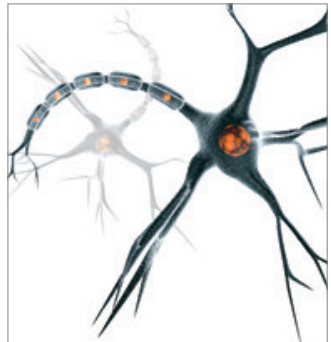

Neural Plasticity
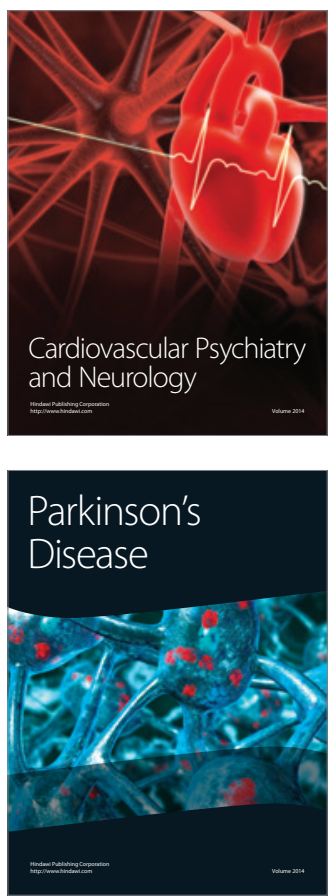